\title{
Detection and genetic characterization of a wide range of infectious agents in Ixodes pavlovskyi ticks in Western Siberia, Russia
}

Vera Rar ${ }^{1}$, Natalia Livanova ${ }^{1,2}$, Sergey Tkachev', Galina Kaverina', Artem Tikunov', Yuliya Sabitova', Yana Igolkina', Victor Panov ${ }^{2}$, Stanislav Livanov², Nataliya Fomenko ${ }^{1}$, Igor Babkin ${ }^{1}$ and Nina Tikunova ${ }^{1 *}$ (D)

\begin{abstract}
Background: The Ixodes pavlovskyi tick species, a member of the I. persulcatus/l. ricinus group, was discovered in the middle of the $20^{\text {th }}$ century in the Russian Far East. Limited data have been reported on the detection of infectious agents in this tick species. The aim of this study was to investigate the prevalence and genetic variability of a wide range of infectious agents in I. pavlovskyi ticks collected in their traditional and recently invaded habitats, the Altai Mountains and Novosibirsk Province, respectively, which are both located within the Western Siberian part of the I. pavlovskyi distribution area.
\end{abstract}

Results: This study reports the novel discovery of Borrelia bavariensis, Rickettsia helvetica, $R$. heilongjiangensis, $R$. raoultii, "Candidatus Rickettsia tarasevichiae", Anaplasma phagocytophilum, Ehrlichia muris, "Candidatus Neoehrlichia mikurensis" and Babesia microti in I. pavlovskyi ticks. In addition, we confirmed the previous identification of B. afzelii, B. garinii and B. miyamotoi, as well as tick-borne encephalitis and Kemerovo viruses in this tick species. The prevalence and some genetic characteristics of all of the tested agents were compared with those found in I. persulcatus ticks that were collected at the same time in the same locations, where these tick species occur in sympatry. It was shown that the prevalence and genotypes of many of the identified pathogens did not significantly differ between I. pavlovskyi and I. persulcatus ticks. However, I. pavlovskyi ticks were significantly more often infected by B. garinii and less often by B. bavariensis, B. afzelii, "Ca. R. tarasevichiae", and E. muris than 1. persulcatus ticks in both studied regions. Moreover, new genetic variants of B. burgdorferi (sensu lato) and Rickettsia spp. as well as tick-borne encephalitis and Kemerovo viruses were found in both I. pavlovskyi and I. persulcatus ticks.

Conclusion: Almost all pathogens that were previously detected in I. persulcatus ticks were identified in I. pavlovskyi ticks; however, the distribution of species belonging to the B. burgdorferi (sensu lato) complex, the genus Rickettsia, and the family Anaplasmataceae was different between the two tick species. Several new genetic variants of viral and bacterial agents were identified in I. pavlovskyi and I. persulcatus ticks.

Keywords: Ixodes pavlovskyi, Ixodes persulcatus, Tick-borne encephalitis virus, Kemerovo virus, Borrelia burgdorferi (sensu lato), Borrelia miyamotoi, Rickettsia spp, Anaplasmataceae, Babesia microti, Western Siberia

\footnotetext{
* Correspondence: tikunova@niboch.nsc.ru

${ }^{1}$ Institute of Chemical Biology and Fundamental Medicine, SB RAS,

Novosibirsk, Russian Federation

Full list of author information is available at the end of the article
} 


\section{Background}

In the Northern Hemisphere, at least five tick species of the genus Ixodes (Ixodidae) can transmit a great variety of infectious agents to humans: I. ricinus, I. persulcatus, I. scapularis, I. ovatus, I. pacificus and I. hexagonus. The most important pathogens vectored by these Ixodes ticks are a number of bacteria of the Borrelia burgdorferi (sensu lato) (s.l.) complex and tick-borne encephalitis virus (TBEV) from the family Flaviviridae [1-11]. In addition, the causative agents of rickettsioses, relapsing fever borreliosis, ehrlichiosis, anaplasmosis, neoehrlichiosis, babesiosis, tularemia and bartonellosis can be detected in these tick species [9, 10, 12-22]. Moreover, a number of pathogens of veterinary importance can also be vectored by these Ixodes ticks [23, 24]. A large number of studies of the ecology, geographical distribution, and genetic variability of I. ricinus, I. scapularis and $I$. pacificus ticks and the molecular epidemiology of pathogens transmitted by them have been published $[4,7,9,10,12,25-28]$. The ability of I. persulcatus ticks to transmit the Far Eastern subtype of TBEV, which causes a severe neurological disease, and the wide distribution area of this tick species have led to the sustained attention of investigators from Russia on this tick species. This has resulted in the accumulation of data on the biology, occurrence and medical importance of $I$. persulcatus ticks, although some of this information is available only in the Russian scientific literature [1, 3, 29-38]. In Russia, TBEV, Kemerovo virus (KEMV), B. afzelii, B. bavariensis, B. garinii, B. valaisiana, B. miyamotoi, Rickettsia heilongiiangensis, $R$. helvetica, R. raoultii, $R$. sibirica, "Candidatus Rickettsia tarasevichiae", Anaplasma phagocytophilum, Ehrlichia muris, "Candidatus Neoehrlichia mikurensis", Babesia microti, Bab. venatorum and Bartonella spp. have all been found in I. persulcatus ticks [3, 5, 14, 15, 39-51].

In the middle of the $20^{\text {th }}$ century, a new species of Ixodes ticks, I. pavlovskyi, was discovered in the Russian Far East [52]. This tick species, belonging to the $I$. persulcatus/I. ricinus group, has a discontinuous distribution area, including the Far Eastern (southern areas of the Russian Far East Manchuria in China and northern regions in Japan) and Western Siberian (Altai and Kuznetsk Alatau Mountains and Salair Ridge) regions $[1,53]$. In the last century, single $I$. pavlovskyi ticks have been recorded in more northern sites located in the Western Siberian Plain, but these findings have been rare [29]. Ixodes pavlovskyi ticks are morphologically and genetically similar to $I$. persulcatus, occur in sympatry, and have a comparable ecology [54-58]. Their activity seasons overlap, and larvae and nymphs of both tick species usually feed on the same hosts [1]. However, I. persulcatus adults feed on large and medium-sized wild mammals and livestock, while I. pavlovskyi adults feed on birds that collect food from the ground and have been found to feed on the European hedgehog (Erinaceus europaeus), the mountain hare (Lepus timidus), and the red squirrel (Sciurus vulgaris) [59, 60]. Notably, natural hybridization between I. pavlovskyi and I. persulcatus ticks in their sympatric populations in Western Siberia has been described [61]. From the beginning of this century, an increased abundance of I. pavlovskyi ticks has been recorded more northward in Western Siberia in parks and suburban areas of Novosibirsk and Tomsk, large Siberian cities situated in the Western Siberian Plain. In these suburban areas, I. pavlovskyi ticks have become predominant in a number of locations, reaching $82-94 \%$ of tick samplings $[35,58,62,63]$. Ixodes pavlovskyi ticks frequently attack people $[1,64,65]$; however, the role of the tick species in the epidemiology of tick-borne diseases has not been studied. The natural locations inhabited by sympatric populations of I. pavlovskyi and I. persulcatus are poorly characterized. The cause of the recent expansion of $I$. pavlovskyi ticks is unknown. Limited data have been reported on the detection of tickborne pathogens in these ticks, including TBEV, KEMV, $B$. afzelii, B. garinii and B. miyamotoi [36, 43, 48, 51, 66, 67]. In addition, DNA of $A$. phagocytophilum and " $C a$. N. mikurensis" were identified in I. pavlovskyi ticks when a bacterial community associated with this tick species was studied by metagenomics $16 \mathrm{~S}$ profiling [68].

In this study, a wide range of infectious agents was investigated in I. pavlovskyi ticks collected in their previously known habitat in the Northern part of the Altai Mountains, as well as in their recently recorded habitat near Novosibirsk, Western Siberia, Russia. In addition, the prevalence and genetic divergence of detected agents were compared with those found in well-known $I$. persulcatus ticks that were simultaneously caught in the same locations.

\section{Methods \\ Field study}

Questing Ixodes spp. ticks were collected by flagging along linear transects in May-June of 2010-2015 in two locations in Western Siberia, Russia: in the northern part of the Altai Mountains, Republic of Altai (two sites) and in parks and suburbs of the city of Novosibirsk, Novosibirsk Province (five sites) (Fig. 1). The description of the sampling sites is given in Table 1.

The species, sex, and stage of collected ticks were determined using a binocular microscope, according to morphological keys [1]. Differentiation of I. pavlovskyi from $I$. persulcatus ticks was based on the following morphological criteria: conscutum color, scapular grooves profile, punctuations and form of the scutum, form of the auriculae, and form of the basis capituli. 


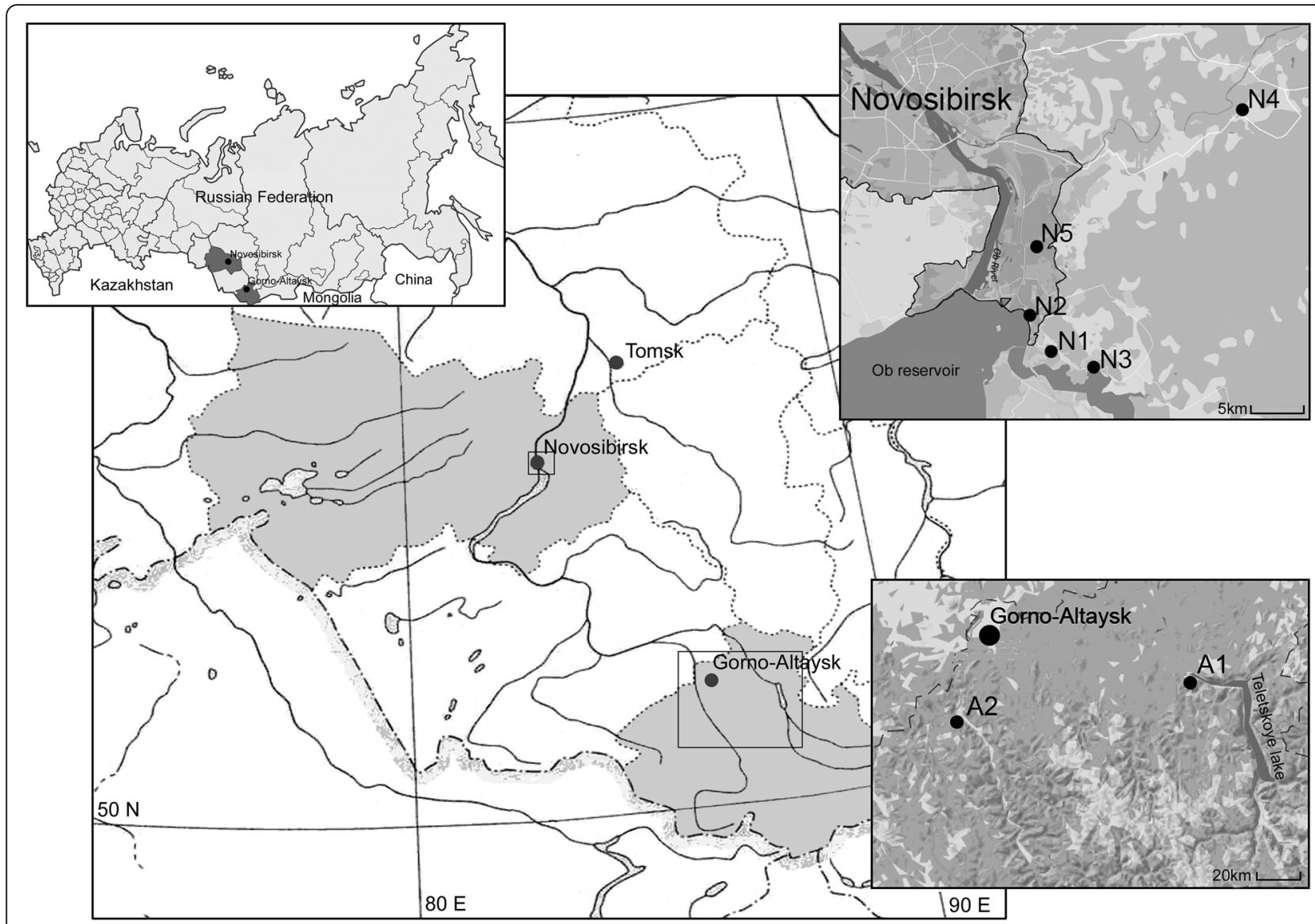

Fig. 1 Sites of tick collections in Western Siberia. Legend: A1-A2, sites located in the Republic of Altai; N1-N5, sites located in Novosibirsk Province

Adult ticks that could not be clearly identified as $I$. pavlovskyi or $I$. persulcatus as well as nymphs were excluded from this study.

\section{DNA extraction}

To prevent cross-contamination, DNA extraction, amplification, and PCR product detection were carried out in separate rooms. Aerosol-free pipette tips were used at each stage. Ticks were individually washed with bi-distilled water, $70 \%$ ethanol and bi-distilled water once more. Afterwards, ticks were homogenized with a MagNA Lyser system (Roche Applied Science, Germany) and used for the isolation of total nucleic acids using a Proba NK kit (DNA-Technology, Moscow, Russia) according to the manufacturer's protocol; nucleic acid samples were stored at $-70{ }^{\circ} \mathrm{C}$.

\section{Genetic characterization of ticks}

Two genetic loci were used to confirm the species identities of Ixodes ticks: the mitochondrial cytochrome $c$ oxidase subunit 1 ( $\operatorname{cox} 1)$ gene and the nuclear internal transcribed spacer (ITS2). For species determination based on the cox 1 gene, species-specific PCR on the nucleic acid specimen of each tick was carried out with previously designed primers [69]: Ixodes-F and Ipers- $R$, specific to I. persulcatus, and Ixodes-F and Ipav-R, specific to I. pavlovskyi (Table 2). The lengths of the PCR fragments were 689-690 bp. In addition, sequencing of the nuclear genome fragment ITS2, amplified using the primers F-ITS2 and R1-ITS2 (Table 2), which have been described previously [58], was used for genetic characterization of each tick. The lengths of the PCR fragments were 632-636 bp.

\section{Detection and genotyping of KEMV and TBEV}

cDNA was synthesized by reverse transcription performed using a RevertaL-100 kit containing random hexanucleotides (Amplisence, Moscow, Russia), with total nucleic acids isolated from ticks as the template. Primers specific to E-NS1 gene sequences of all TBEV subtypes were used for the primary (E7 and E10) and nested (E9 and E8) reactions (Table 2) [34]. For KEMV detection, primers specific to KEMV genome segment 1 sequences were designed for primary (Kem1s_1 and Kem1s_2) and nested (Kem1s_3 and Kem1s_4) reactions (Table 2) [70]. 


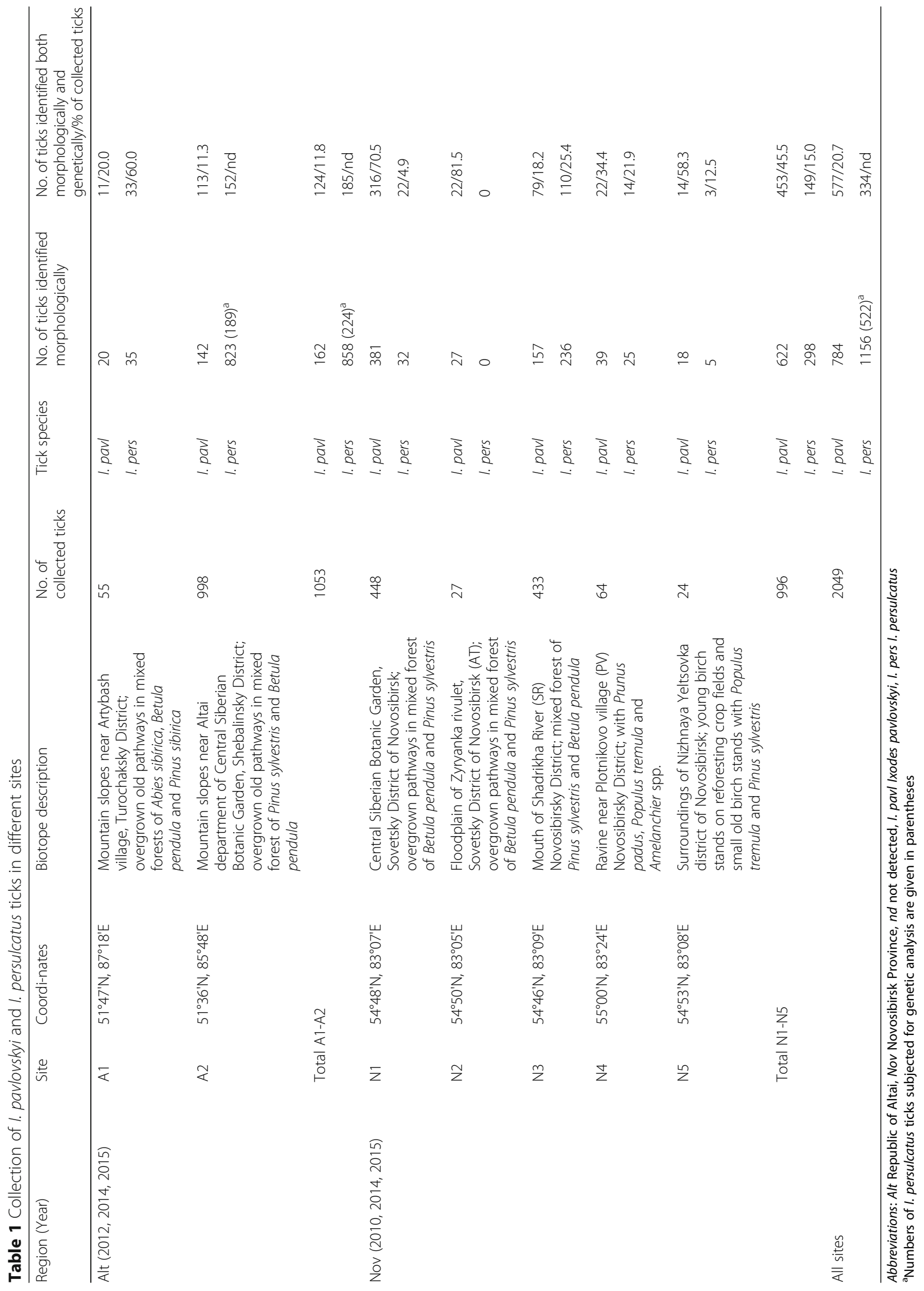


Table 2 Primers used for PCR

\begin{tabular}{|c|c|c|c|}
\hline Amplified locus & Primer sequences $\left(5^{\prime}-3^{\prime}\right)$ & Annealing temperature & Reference \\
\hline Ixodes sp. ITS2 & $\begin{array}{l}\text { F-ITS2 (cacactgagcacttactctttg) } \\
\text { R1-ITS2 (actggatggctccagtattc) }\end{array}$ & $57^{\circ} \mathrm{C}$ & {$[58]$} \\
\hline 1. persulcatus cox 1 gene & $\begin{array}{l}\text { Ixodes-F (acctgatatagctttccctcg) } \\
\text { Ipers-R (ttgattcctgttggaacagc) }\end{array}$ & $55^{\circ} \mathrm{C}$ & [69] \\
\hline 1. pavlovskyi cox 1 gene & $\begin{array}{l}\text { Ixodes-F (acctgatatagctttccctcg) } \\
\text { Ipav-R (taatccccgtggggacg) }\end{array}$ & $55^{\circ} \mathrm{C}$ & [69] \\
\hline \multirow[t]{2}{*}{ TBEV E-NS1 genes } & $\begin{array}{l}\text { E7 (ggcatagaaaggctgacagtg) } \\
\text { E10 (gatacctctctccacacaaccag) }\end{array}$ & $52^{\circ} \mathrm{C}$ & [34] \\
\hline & $\begin{array}{l}\text { E9 (acagtgataggagaacacgcctggg) } \\
\text { E8 (cagccaggaggaagctcatggac) }\end{array}$ & $52^{\circ} \mathrm{C}$ & [34] \\
\hline \multirow[t]{2}{*}{ KEMV segment 1} & $\begin{array}{l}\text { Kem1s_1 (attcaaattacgacacgcacatgac) } \\
\text { Kem1s_2 (gtatcgtcgccgacgtacatctc) }\end{array}$ & $56^{\circ} \mathrm{C}$ & [70] \\
\hline & $\begin{array}{l}\text { Kem1s_3 (gctcatcgaagcgggatacgg) } \\
\text { Kem1s_4 (gcgtagagttctctcccgacagatg) }\end{array}$ & $56^{\circ} \mathrm{C}$ & [70] \\
\hline \multirow[t]{2}{*}{$\begin{array}{l}\text { Borrelia burgdorferi (s.l.) 5S-23S rRNA } \\
\text { intergenic spacer }\end{array}$} & $\begin{array}{l}\text { NC1 (cctgttatcattccgaacacag) } \\
\text { NC2 (tactccattcggtaatcttggg) }\end{array}$ & $50^{\circ} \mathrm{C}$ & [14] \\
\hline & $\begin{array}{l}\text { NC3 (tactgcgagttcgcgggag) } \\
\text { NC4 (cctaggcattcaccatagac) }\end{array}$ & $54{ }^{\circ} \mathrm{C}$ & [71], modified \\
\hline \multirow[t]{2}{*}{$\begin{array}{l}\text { B. miyamotoi } \\
\text { glpQ gene }\end{array}$} & $\begin{array}{l}\text { Q1 (caccattgatcatagctcacag) } \\
\text { Q4 (ctgttggtgcttcattccagtc) }\end{array}$ & $50^{\circ} \mathrm{C}$ & [44] \\
\hline & $\begin{array}{l}\text { Q3 (gctagtgggtatcttccagaac) } \\
\text { Q2 (cttgttgtttatgccagaagggt) }\end{array}$ & $54^{\circ} \mathrm{C}$ & [44] \\
\hline \multirow[t]{2}{*}{$\begin{array}{l}\text { B. burgdorferi (s.l.) } \\
\text { p83/100 gene }\end{array}$} & $\begin{array}{l}\text { F7 (ttcaaagggatactgttagagag) } \\
\text { F10 (aagaaggcttatctaatggtgatg) }\end{array}$ & $50^{\circ} \mathrm{C}$ & This study \\
\hline & $\begin{array}{l}\text { F5 (acctggtgatgtaagttctcc) } \\
\text { F12 (ctaacctcattgttgttagactt) }\end{array}$ & $54{ }^{\circ} \mathrm{C}$ & This study \\
\hline \multirow[t]{2}{*}{$\begin{array}{l}\text { B. burgdorferi (s.l.) } \\
\text { clpA gene }\end{array}$} & $\begin{array}{l}\text { clpAF1237 (aaagatagatttcttccagac) } \\
\text { clpAR2218 (gaatttcatctattaaaagctttc) }\end{array}$ & $55 \rightarrow 48^{\circ} \mathrm{C}$ & [72] \\
\hline & $\begin{array}{l}\text { clpAF1255 (gacaaagcttttgatattttag) } \\
\text { clpAR2104 (caaaaaaaacatcaaattttctatctc) }\end{array}$ & $50^{\circ} \mathrm{C}$ & [72] \\
\hline \multirow[t]{2}{*}{$\begin{array}{l}\text { Anaplasmataceae } \\
16 \mathrm{~S} \text { rRNA gene }\end{array}$} & $\begin{array}{l}\text { Ehr1 (gaacgaacgctggcggcaagc) } \\
\text { Ehr2 (agtaycgraccagatagccgc) }\end{array}$ & $57^{\circ} \mathrm{C}$ & [45] \\
\hline & $\begin{array}{l}\text { Ehr3 (tgcataggaatctacctagtag) } \\
\text { Ehr4 (ctaggaattccgctatcctct) }\end{array}$ & $60^{\circ} \mathrm{C}$ & [45] \\
\hline $\begin{array}{l}\text { A. phagocytophilum } \\
16 S \text { rRNA gene }\end{array}$ & $\begin{array}{l}\text { HGE1 (cggattattctttatagcttgc) } \\
\text { HGE2 (cttaccgaaccgcctacatg) }\end{array}$ & $55^{\circ} \mathrm{C}$ & [45] \\
\hline $\begin{array}{l}\text { E. muris } \\
16 S \text { rRNA gene }\end{array}$ & $\begin{array}{l}\text { Em1 (cgaacggatagctacccatagc) } \\
\text { Em2 (cgctccaaagttaagctttggt) }\end{array}$ & $55^{\circ} \mathrm{C}$ & [45] \\
\hline \multirow[t]{2}{*}{$\begin{array}{l}\text { Anaplasmataceae } \\
\text { groESL operon }\end{array}$} & $\begin{array}{l}\text { HS1-f (cgycagtgggctggtaatgaa) } \\
\text { HS6-r (ccwccwggtacwacaccttc) }\end{array}$ & $55^{\circ} \mathrm{C}$ & [73], modified \\
\hline & $\begin{array}{l}\text { HS3-f (atagtyatgaaggagagtgat) } \\
\text { HSVR (tcaacagcagctctagtwg) }\end{array}$ & $50^{\circ} \mathrm{C}$ & [74] \\
\hline \multirow[t]{2}{*}{$\begin{array}{l}\text { Rickettsia spp. } \\
\text { gltA gene }\end{array}$} & $\begin{array}{l}\text { glt1 (gattgctttacttacgaccc) } \\
\text { glt2 (tgcatttctttccattgtgc) }\end{array}$ & $52^{\circ} \mathrm{C}$ & [49] \\
\hline & $\begin{array}{l}\text { glt3 (tatagacggtgataaaggaatc) } \\
\text { glt4 (cagaactaccgatttctttaagc) }\end{array}$ & $53^{\circ} \mathrm{C}$ & [49] \\
\hline "Ca. R. tarasevichiae" gltA gene & $\begin{array}{l}\text { RT1 (tactaaaaaagtcgctgttcattc) } \\
\text { RT2 (tgttgcaaacatcatgcgtaag) }\end{array}$ & $56^{\circ} \mathrm{C}$ & [49] \\
\hline SFGR gltA & $\begin{array}{l}\text { RH1 (gtcagtctactatcacctatatag) } \\
\text { RH3 (taaaatattcatctttaagagcga) }\end{array}$ & $54{ }^{\circ} \mathrm{C}$ & $\begin{array}{l}{[49]} \\
\text { This study }\end{array}$ \\
\hline \multirow[t]{2}{*}{$\begin{array}{l}\text { Babesia spp. } \\
18 \mathrm{~S} \text { rRNA gene }\end{array}$} & $\begin{array}{l}\text { BS1 (gacggtagggtattggcct) } \\
\text { BS2 (attcaccggatcactcgatc) }\end{array}$ & $58^{\circ} \mathrm{C}$ & [46] \\
\hline & $\begin{array}{l}\text { BS3 (taccggggcgacgacgggtg) } \\
\text { BS5 (cgaggcagcaacgggtaacg) } \\
\text { BS4 (agggacgtagtcggcacgag) }\end{array}$ & $62^{\circ} \mathrm{C}$ & [46] \\
\hline
\end{tabular}




\section{Borrelia spp. nucleic acid detection}

Detection of Borrelia DNA was carried out using multiplex nested PCR with primers specific to the $5 \mathrm{~S}$ and $23 \mathrm{~S}$ rRNA gene fragments flanking the intergenic spacer of B. burgdorferi (s.l.) and to the $g l p Q$ gene of B. miyamotoi, which were designed previously [14, 44, 71]. The primers $\mathrm{NC1}, \mathrm{NC} 2$ and $\mathrm{Q} 1, \mathrm{Q} 4$ were used for primary reactions, while primers $\mathrm{NC} 3, \mathrm{NC4}$ and Q2, Q3 were used for nested reactions (Table 2). The length of the nested PCR products was 246-253 bp for B. burgdorferi (s.l.) and 424 bp for B. miyamotoi.

To identify bacteria species from the B. burgdorferi (s.l.) complex (with the exception of mixed Borrelia infection), nested PCR with primers specific to the $\operatorname{clpA}$ gene was carried out; primers clpAF1237 and clpAR2218 were used for primary reactions, and primers clpAF1255 and clpAR2104 were used for nested reactions, as described previously [72]. The length of the nested PCR products was 849 bp for all B. burgdorferi (s.l.) species. In addition, these samples were amplified using primers specific to the $p 83 / 100$ gene; primers $\mathrm{F} 7$ and F10 were used for primary reactions, and primers F5 and F12 were used for nested reactions (Table 2). The length of the nested PCR products was $336 \mathrm{bp}$ for $B$. afzelii, 426-462 bp for B. bavariensis and B. garinii, and $420 \mathrm{bp}$ for B. valaisiana.

All amplified clpA and $p 83 / 100$ gene fragments of $B$. burgdorferi (s.l.) and glpQ gene fragments of B. miyamotoi were sequenced. To discriminate the closely related $B$. garinii and B. bavariensis, the determined $\operatorname{clpA}$ gene sequences were analyzed using the MLST website (http://pubmlst.org/borrelia/), while the $p 83 / 100$ gene sequences were compared with corresponding sequences of B. bavariensis strains PBi (GenBank CP000013), NMJW1 (GenBank CP003866), and BgVir (GenBank CP003202) and B. garinii strains N34 (GenBank AY583360), Tom203 (GenBank DQ916329), and Tom3305 (GenBank DQ916322), all of which are available in the GenBank database.

\section{Detection and genotyping of Rickettsia spp.}

For screening analysis, Rickettsia DNA was detected by nested PCR of the gltA gene using primers glt1 and glt2 for primary reactions and glt3 and glt4 for nested reactions, as described previously [49]. To identify Rickettsia spp. in positive samples, nested reactions were performed independently using primers RT1 and RT2, specific to "Ca. R. tarasevichiae", and RH1 and RH3, specific to spotted fever group rickettsiae (SFGR) (Table 2). The amplified gltA gene fragments of all ticks that were positive for SFGR and some that were positive for "Ca. R. tarasevichiae" were sequenced.
Detection and genotyping of Anaplasmataceae bacteria Detection of Anaplasmataceae bacteria with subsequent species determination was conducted using nested PCR assays as described previously [45]. For screening analysis, Anaplasmataceae DNA was detected by nested PCR based on the 16S rRNA gene. The primers Ehr1 and Ehr2 were used for primary reactions and the primers Ehr3 and Ehr4 were used for nested reactions (Table 2); the final products were $524 \mathrm{bp}$ in length. For all positive samples, nested reactions were performed with primers specific to A. phagocytophilum, HGE1 and HGE2, and primers specific to E. muris, Em1 and Em2 (Table 2). For sequence analysis, fragments of the groESL operon with a length of 1320-1360 bp were amplified using the primers HS1-f and HS6-r (modified HS1 and HS6 primers [73]) for the primary reactions and the primers HS3-f and HSVR [74] for nested reactions.

\section{Detection and genotyping of Babesia spp.}

Babesia DNA was detected by nested PCR for the presence of the 18S rRNA gene, as described previously [46]. Primary reactions were carried out using the forward primer BS1 and the reverse primer BS2. Nested reactions were carried out as multiplex reactions using the forward primers BS3 and BS5 and the reverse primer BS4 (Table 2). The BS3 primer was specific for the Bab. microti group, while the BS5 primer was specific for the Babesia (sensu stricto) group. All amplified Babesia spp. $18 \mathrm{~S}$ rRNA gene fragments were sequenced.

\section{Sequencing and phylogenetic analysis}

The PCR products were purified using GeneJET Gel Extraction Kit (ThermoFisher Scientific, Vilnius, Lithuania). The Sanger sequencing reactions were conducted using "BigDye ${ }^{\mathrm{Tx}}$ Terminator v. 3.1 Cycle Sequencing kit" (Applied Biosystems Inc., Austin, TX, USA) in both directions with primers indicated in Table 2. The corresponding products were analyzed using an $\mathrm{ABI}$ 3500 Genetic Analyzer (Applied Biosystems Inc.). All obtained sequences were compared with those of reference strains available in the NCBI website using the BLASTN 2.2.31+ (https://blast.ncbi.nlm.nih.gov/Blast.cgi). Molecular phylogenetic analyses were conducted using Maximum Likelihood (ML) method based on Hasegawa-KishinoYano (HKY) nucleotide substitution model in MEGA 7.0 with 1000 bootstrap replicates [75].

\section{Statistical analysis}

Statistical analysis was performed to compare the proportion of collected Ixodes spp. from various locations and prevalence of causative agents in different tick species. The 95\% confidence intervals (CI) for the prevalence of infectious agents in questing ticks were computed using an Excel spreadsheet (http://www.pedro.org.au/english/ 
downloads/confidence-interval-calculator/). Differences in the prevalence of infectious agents in I. pavlovskyi and $I$. persulcatus ticks per region were computed using the Pearson $X^{2}$ goodness-of-fit test (http://www.socscistatistics.com/tests/chisquare/). $\quad P<0.05$ was regarded as significant.

\section{Nucleotide sequence accession numbers}

Nucleotide sequences determined in this study were deposited in the GenBank database under the following accession numbers: KY002831-KY002882, for TBEV; KX834332, KX834343, KX834344 and KX834341 for KEMV; KX980208-KX980214 (clpA) and KX980275KX980287 (p83/100) for B. afzelii; KX980215KX980232 (clpA) and KX980288-KX980313 (p83/100) for B. bavariensis; KX980233-KX980273 (clpA) and KX980314-KX980349 (p83/100) for $B$. garinii; KX980274 $(\operatorname{clp} A)$ and KX980350 (p83/100) for $B$. valaisiana; KY006159-KY006162 for B. miyamotoi; KX963401-KX963404 for $R$. heilongjiangensis; KX963385-KX963388 for $R$. helvetica; KX963389KX963395, KY019068 and KY056616-KY056618 for $R$. raoultii; KX963396-KX963400 and KY019069 for $R$. sibirica; KX963381-KX963384 for “Ca. R. tarasevichiae”; KX963405-KX963406 for Rickettsia spp.; KX980041KX980046 for A. phagocytophilum; KX980047KX980049 for E. muris; KX980039-KX980040 for "Ca. N. mikurensis"; KX987863 and KX987864 for Bab. microti.

\section{Results}

\section{Tick species determination}

Adult questing Ixodes spp. ticks were collected by flagging in two regions within the Western Siberian part of the I. pavlovskyi distribution area. Sites A1 and A2 were located in the northern part of the Altai Mountains ( $\mathrm{Re}$ public of Altai), within the previously known distribution area of this species, while sites N1-N5 were located more northward, in the Western Siberia Plain (Novosibirsk Province), a recently invaded habitat of I. pavlovskyi ticks (Fig. 1). Sites A1 and A2 were located on mountain slopes with relatively low human influence, while Sites N1-N5 were located in parks and suburban areas of the city of Novosibirsk and are characterized by a substantial anthropogenic impact. A total of 2049 adult Ixodes ticks were collected in all sites. Of these, 1053 individuals were caught in the Altai Mountains and 996 in the Novosibirsk Province (Table 1).

Tick species were determined using morphological keys and two genetic loci, the mitochondrial cox 1 gene and the nuclear ITS2. According to their morphology, 784 ticks collected from both regions were identified as I. pavlovskyi and 1156 as I. persulcatus (Table 1). Then, all morphologically identified I. pavlovskyi ticks and 522
I. persulcatus ticks were tested genetically (only 189 of the 823 ticks collected at Site A2 and defined as $I$. persulcatus using morphological keys were subjected to further genetic analysis) (Table 1). Only ticks with both morphological and genetic criteria corresponding to the same tick species were identified as that species. All morphological intermediates and ticks with a mitochondrial locus belonging to one species and a nuclear locus to another species were excluded from this investigation. Therefore, 577 I. pavlovskyi and 334 I. persulcatus ticks that complied with both the morphological and genetic criteria were examined for the presence of ticktransmitted agents (Tables 1 and 3).

Ixodes pavlovskyi ticks were identified in all studied sites from both the Altai Mountains and Novosibirsk surroundings. The proportion of this tick species in the Altai Mountains was $11.8 \%$ (124/1053), varying from 11.3 to $20 \%$ in different sites (Table 1 ). In the suburbs of Novosibirsk, the proportion of $I$. pavlovskyi ticks was $48.5 \%$ (453/996) and ranged from 18.2 to $81.5 \%$ in different sites, which was significantly higher $\left(\chi^{2}=287.450\right.$, $d f=1, P<0.001)$ than in the Altai Mountains. Ixodes persulcatus ticks were detected in almost all sites, with the exception of Site N2 from Novosibirsk Province, in which only 27 ticks were caught. In all other sites from the suburbs of Novosibirsk, the proportion of I. persulcatus ticks was $15.4 \%$ (149/996), varying from 4.9 to $25.4 \%$ in different sites (Table 1), which was a significantly lower proportion than that observed for I. pavlovskyi $\left(\chi^{2}=220.001, d f=1, P<0.001\right)$.

\section{Detection and genotyping of TBEV and KEMV RNA}

The TBEV prevalence in I. pavlovskyi and I. persulcatus ticks collected in both the Altai Mountains and Novosibirsk suburbs was 5.9\% (34/577; 95\% CI: 4.3-8.1) and 5.4\% (18/334; 95\% CI: 3.4-8.4), respectively (Table 3), which was not significantly different $\left(\chi^{2}=0.100, d f=1\right.$, $P=0.752$ ) (Table 4). The sequences of TBEV isolates from most of the $I$. pavlovskyi and I. persulcatus ticks collected in both the Republic of Altai and Novosibirsk Province were related to each other and belonged to both the Vasilchenko and Zausaev lineages of the Siberian subtype. Among those belonging to the Zausaev lineage, several isolates detected in I. pavlovskyi ticks from Novosibirsk Province (KY002872-KY002874, KY002880) formed a separate cluster on the phylogenetic tree (Fig. 2). In addition, two TBEV isolates belonging to the European subtype were discovered in $I$. pavlovskyi ticks (KY002846, KY002848), which is the first reported finding of this subtype in this tick species (Fig. 2). Moreover, one TBEV isolate detected in an $I$. pavlovskyi tick (KY002870) collected from Site N1 (Novosibirsk Province) belonged to a putative new TBEV subtype currently named "886-84", which was 


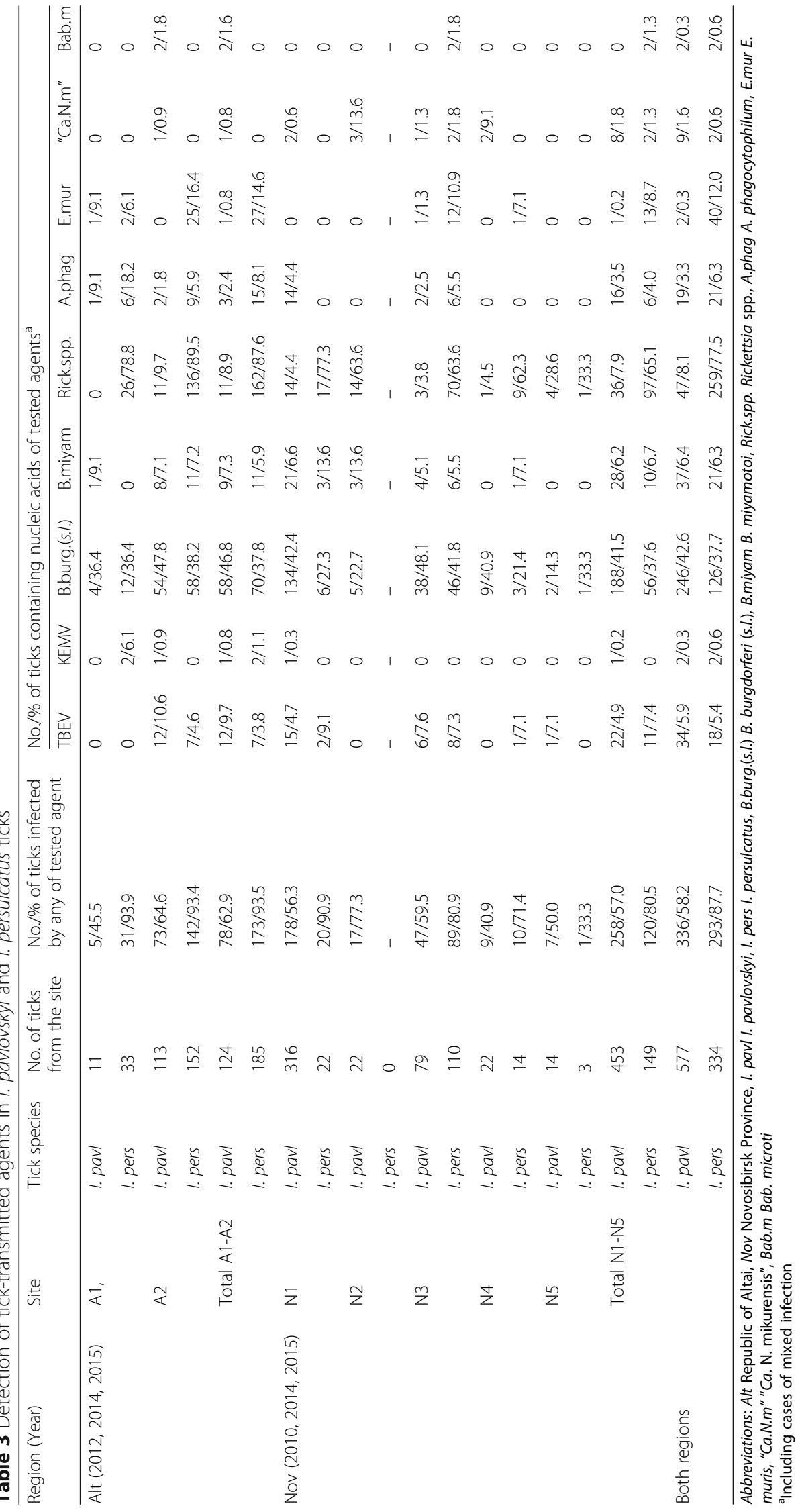


Table 4 Overall prevalence of tick-transmitted agents in I. pavlovskyi and I. persulcatus ticks per region

\begin{tabular}{|c|c|c|c|c|c|c|}
\hline Region & $\begin{array}{l}\text { I. pavlovskyi } \\
\% \text { (pos/total) }\end{array}$ & $95 \% \mathrm{Cl}$ & $\begin{array}{l}\text { 1. persulcatus } \\
\% \text { (pos/total) }\end{array}$ & $95 \% \mathrm{Cl}$ & $x^{2}$ & $P$ \\
\hline \multicolumn{7}{|l|}{ TBEV } \\
\hline Alt & $9.7(12 / 124)$ & $5.6-16.2$ & $3.8(7 / 185)$ & $1.8-7.6$ & 4.469 & 0.035 \\
\hline Nov & $4.9(22 / 453)$ & $3.2-7.2$ & $7.4(11 / 149)$ & $4.2-12.7$ & 1.381 & 0.240 \\
\hline Total & $5.9(34 / 577)$ & $4.3-8.1$ & $5.4(18 / 334)$ & $3.4-8.4$ & 0.100 & 0.752 \\
\hline \multicolumn{7}{|l|}{ KEMV } \\
\hline Alt & $0.8(1 / 124)$ & $0.1-4.4$ & $1.1(2 / 185)$ & $0.3-3.9$ & 0.054 & 0.816 \\
\hline Nov & $0.2(1 / 453)$ & $0.0-1.2$ & $0(0 / 149)$ & - & 0.330 & 0.566 \\
\hline Total & $0.3(2 / 577)$ & $0.1-1.3$ & $0.6(2 / 334)$ & $0.2-2.2$ & 0.308 & 0.579 \\
\hline \multicolumn{7}{|l|}{ B. afzelii } \\
\hline Alt & $2.4(3 / 124)$ & $0.8-6.9$ & $10.3(19 / 185)$ & $6.7-15.5$ & 6.920 & 0.009 \\
\hline Nov & $1.1(5 / 453)$ & $0.5-2.6$ & $13.4(20 / 149)$ & 8.9-19.8 & 42.749 & $<0.001$ \\
\hline Total & $1.4(8 / 577)$ & $0.7-2.7$ & $11.7(39 / 334)$ & $8.7-15.6$ & 45.780 & $<0.001$ \\
\hline \multicolumn{7}{|c|}{ B. bavariensis } \\
\hline Alt & $0(0 / 124)$ & - & $27.0(50 / 185)$ & $21.1-33.9$ & 39.983 & $<0.001$ \\
\hline Nov & $1.3(6 / 453)$ & $0.6-2.9$ & $18.8(28 / 149)$ & $13.3-25.8$ & 64.197 & $<0.001$ \\
\hline Total & $1.0(6 / 577)$ & $0.5-2.3$ & $23.4(78 / 334)$ & $19.1-28.2$ & 125.853 & $<0.001$ \\
\hline \multicolumn{7}{|l|}{ B. garinii } \\
\hline Alt & $45.2(56 / 124)$ & $36.7-53.9$ & $2.7(5 / 185)$ & $1.2-6.2$ & 84.470 & $<0.001$ \\
\hline Nov & $39.3(178 / 453)$ & $34.9-43.9$ & $8.7(13 / 149)$ & $5.2-14.4$ & 48.368 & $<0.001$ \\
\hline Total & $40.6(234 / 577)$ & $38.2-46.2$ & $5.4(18 / 334)$ & $3.4-8.4$ & 130.733 & $<0.001$ \\
\hline \multicolumn{7}{|c|}{ B. valaisiana } \\
\hline Alt & $0(0 / 124)$ & - & $0(0 / 185)$ & - & - & - \\
\hline Nov & $0(0 / 453)$ & - & $0.7(1 / 149)$ & $0.1-3.7$ & 3.045 & 0.081 \\
\hline Total & $0(0 / 577)$ & - & $0.3(1 / 334)$ & $0.1-1.7$ & 1.724 & 0.189 \\
\hline \multicolumn{7}{|c|}{ All B. burgdorferi (s.l.) } \\
\hline Alt & $46.8(58 / 124)$ & $38.2-55.5$ & $37.8(70 / 185)$ & $31.2-45.0$ & 2.443 & 0.118 \\
\hline Nov & $41.5(188 / 453)$ & $37.1-46.1$ & $37.6(56 / 149)$ & $30.0-45.6$ & 0.714 & 0.398 \\
\hline Total & $42.6(246 / 577)$ & $38.7-46.7$ & $37.7(126 / 334)$ & $32.7-43.0$ & 2.111 & 0.146 \\
\hline \multicolumn{7}{|c|}{ B. miyamotoi } \\
\hline Alt & $7.3(9 / 124)$ & $3.9-13.2$ & $5.9(11 / 185)$ & $3.4-10.3$ & 0.211 & 0.646 \\
\hline Nov & $6.2(28 / 453)$ & $4.3-8.8$ & $6.7(10 / 149)$ & $3.7-11.9$ & 0.053 & 0.817 \\
\hline Total & $6.4(37 / 577)$ & $4.7-8.7$ & $6.3(21 / 334)$ & $4.2-9.4$ & 0.006 & 0.941 \\
\hline \multicolumn{7}{|c|}{ R. heilongjiangensis } \\
\hline Alt & $0.8(1 / 124)$ & $0.1-4.4$ & $0.5(1 / 185)$ & $0.1-3.0$ & 0.082 & 0.775 \\
\hline Nov & $0.9(4 / 453)$ & $0.3-2.3$ & $0(0 / 149)$ & - & 1.325 & 0.250 \\
\hline Total & $0.9(5 / 577)$ & $0.4-2.0$ & $0.3(1 / 334)$ & $0.1-1.7$ & 1.040 & 0.308 \\
\hline \multicolumn{7}{|c|}{ R. helvetica } \\
\hline Alt & $8.1(10 / 124)$ & $4.4-14.2$ & $0(0 / 185)$ & - & 15.418 & $<0.001$ \\
\hline Nov & $2.2(10 / 453)$ & $1.2-4.0$ & $0.7(1 / 149)$ & $0.1-3.7$ & 1.475 & 0.225 \\
\hline Total & $3.5(20 / 577)$ & $2.3-5.3$ & $0.3(1 / 334)$ & $0.1-1.7$ & 9.420 & 0.002 \\
\hline
\end{tabular}


Table 4 Overall prevalence of tick-transmitted agents in I. pavlovskyi and I. persulcatus ticks per region (Continued)

\begin{tabular}{|c|c|c|c|c|c|c|}
\hline \multicolumn{7}{|c|}{ R. raoultii } \\
\hline Alt & $0(0 / 124)$ & - & $7.0(13 / 185)$ & $4.2-11.7$ & 9.096 & 0.003 \\
\hline Nov & $3.3(15 / 453)$ & $1.2-4.0$ & $4.7(7 / 149)$ & $2.3-9.4$ & 0.612 & 0.434 \\
\hline Total & $2.6(15 / 577)$ & $1.6-4.2$ & $6.0(20 / 334)$ & $3.9-9.1$ & 6.574 & 0.010 \\
\hline \multicolumn{7}{|c|}{ R. sibirica } \\
\hline Alt & $0(0 / 124)$ & - & $3.2(6 / 185)$ & $1.5-6.7$ & 4.101 & 0.043 \\
\hline Nov & $0(0 / 453)$ & - & $1.3(2 / 149)$ & $0.4-4.8$ & 6.101 & 0.014 \\
\hline Total & $0(0 / 577)$ & - & $2.4(8 / 334)$ & $1.2-4.7$ & 13.942 & $<0.001$ \\
\hline \multicolumn{7}{|c|}{ "Ca. R. tarasevichiae" } \\
\hline Alt & $0.8(1 / 124)$ & $0.1-4.4$ & $87.0(161 / 185)$ & 81.4-91.1 & 221.280 & $<0.001$ \\
\hline Nov & $2.0(9 / 453)$ & $1.0-3.7$ & $61.7(92 / 149)$ & $53.7-69.2$ & 286.759 & $<0.001$ \\
\hline Total & $1.7(10 / 577)$ & $0.9-3.2$ & $75.7(253 / 334)$ & $70.1-80.0$ & 564.357 & $<0.001$ \\
\hline \multicolumn{7}{|c|}{ All Rickettsia spp. } \\
\hline Alt & $8.9(11 / 124)$ & $5.0-15.2$ & $87.6(162 / 185)$ & $82.0-91.6$ & 186.586 & $<0.001$ \\
\hline Nov & $7.9(36 / 453)$ & $5.8-10.8$ & $65.1(97 / 149)$ & $57.2-75.3$ & 212.787 & $<0.001$ \\
\hline Total & $8.1(47 / 577)$ & $6.2-10.7$ & $77.5(259 / 334)$ & $72.8-81.7$ & 456.746 & $<0.001$ \\
\hline \multicolumn{7}{|c|}{ A. phagocytophilum } \\
\hline Alt & $2.4(3 / 124)$ & $0.8-6.9$ & $8.1(15 / 185)$ & $5.0-13.0$ & 4.380 & 0.036 \\
\hline Nov & $3.5(16 / 453)$ & $2.2-5.7$ & $4.0(6 / 149)$ & $1.9-8.5$ & 0.078 & 0.780 \\
\hline Total & $3.3(19 / 577)$ & $2.1-5.1$ & $6.3(21 / 334)$ & $4.2-9.4$ & 4.519 & 0.034 \\
\hline \multicolumn{7}{|l|}{ E. muris } \\
\hline Alt & $0.8(1 / 124)$ & $0.1-4.4$ & $14.6(27 / 185)$ & $10.2-20.4$ & 17.128 & $<0.001$ \\
\hline Nov & $0.2(1 / 453)$ & $0.0-1.2$ & $8.7(13 / 149)$ & $5.2-14.4$ & 35.692 & $<0.001$ \\
\hline Total & $0.3(2 / 577)$ & $0.1-1.3$ & $12.0(40 / 334)$ & $8.9-15.9$ & 65.056 & $<0.001$ \\
\hline \multicolumn{7}{|c|}{ "Ca. N. mikurensis" } \\
\hline Alt & $0.8(1 / 124)$ & $0.1-4.4$ & $0(0 / 185)$ & - & 1.497 & 0.221 \\
\hline Nov & $1.8(8 / 453)$ & $0.9-3.5$ & $1.3(2 / 149)$ & $0.4-4.8$ & 0.123 & 0.726 \\
\hline Total & $1.6(9 / 577)$ & $0.8-2.9$ & $0.6(2 / 334)$ & $0.2-2.2$ & 1.637 & 0.201 \\
\hline \multicolumn{7}{|c|}{ Bab. microti } \\
\hline Alt & $1.6(2 / 124)$ & $0.4-5.7$ & $0(0 / 185)$ & - & 3.003 & 0.083 \\
\hline Nov & $0(0 / 453)$ & - & $1.3(2 / 149)$ & $0.4-4.8$ & 6.101 & 0.014 \\
\hline Total & $0.3(2 / 577)$ & $0.1-1.3$ & $0.6(2 / 334)$ & $0.2-2.2$ & 0.308 & 0.579 \\
\hline
\end{tabular}

Abbreviations: Alt Republic of Altai, Nov Novosibirsk Province, pos/total infected ticks/examined ticks

recently discovered in I. persulcatus ticks and small mammals in the Baikal region as well as in a brain sample of a deceased human in Mongolia [33, 34, 76]. Therefore, this is the first observation of the 886-84 subtype both in $I$. pavlovskyi ticks and in Western Siberia.

RNA of KEMV was found in two I. pavlovskyi ticks from both the Republic of Altai (Site A2) and Novosibirsk Province (Site N1) as well as two I. persulcatus ticks from the Republic of Altai (Site A1) (Table 3). Based on the segment 1 fragment sequence, one KEMV isolate from the I. pavlovskyi tick caught in the Novosibirsk suburbs (KX834332) differed from two corresponding KEMV sequences available in the GenBank database, one belonging to strain
EgAn 1169-61 (GenBank HM543481), isolated in Egypt, and the other to strain 21/10 (GenBank KC288130), isolated from an $I$. persulcatus tick from Kemerovo Province in Western Siberia (identity level of 93.2 and 92.4\%, respectively) (Fig. 3). However, three other KEMV isolates collected in the Altai Mountains, the two isolates from $I$. persulcatus (KX834343 and KX834344) and one from $I$. pavlovskyi (KX834341) ticks, were more closely related to KEMV strain 21/10 (identity level of 95.7-95.8\%).

Detection and genotyping of Borrelia spp. spirochetes Borrelia burgdorferi (s.l.) DNA was found in $42.6 \%$ (246/577; 95\% CI: 38.7-46.7) of I. pavlovskyi ticks 


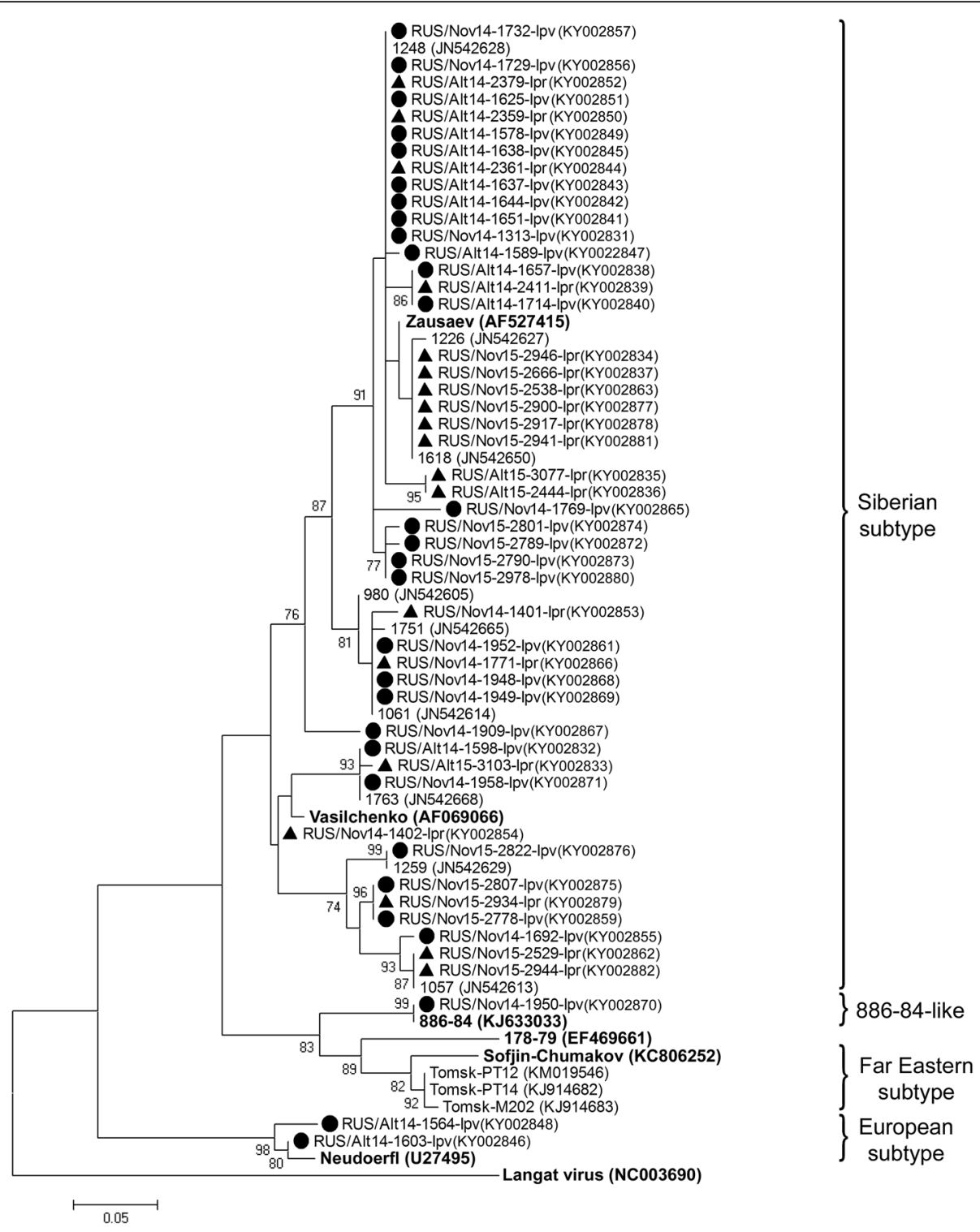

Fig. 2 The phylogenetic tree constructed by the ML method based on nucleotide sequences of 211 bp fragment of the E gene of TBEV. The scale-bar indicates an evolutionary distance of 0.05 nucleotides per position in the sequence. Significant bootstrap values (>70\%) are shown on the nodes. The sequences of prototype TBEV strains and outgroup virus (Langat virus) from GenBank database are in boldface. Legend: • I. pavlovskyi ticks;

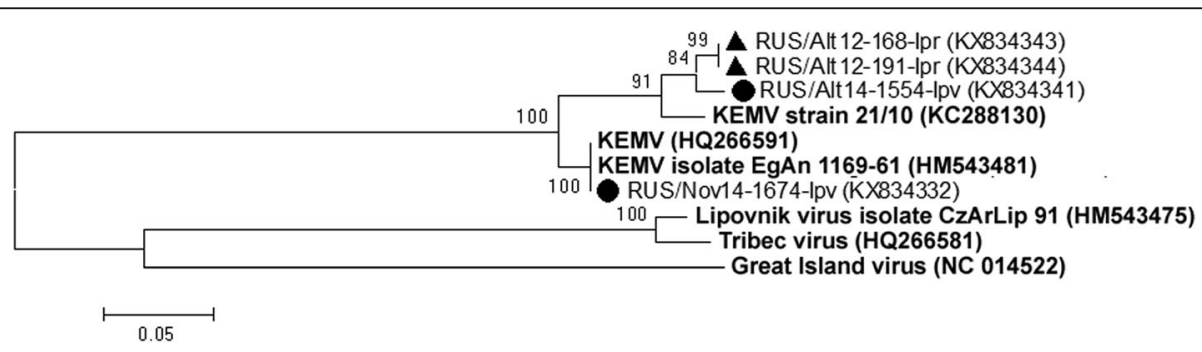

Fig. 3 The phylogenetic tree constructed by the ML method based on nucleotide sequences of 238 bp fragment of KEMV genome segment 1 . The scale-bar indicates an evolutionary distance of 0.05 nucleotides per position in the sequence. Significant bootstrap values (>70\%) are shown on the nodes. The sequences of prototype KEMV strains and outgroup viruses (Great Island, Tribec and Lipovnik viruses) from GenBank database are in boldface. Legend: • I. pavlovskyi ticks; $\boldsymbol{\Delta}$ I. persulcatus ticks 
and $37.7 \%(126 / 334 ; 95 \%$ CI: $32.7-43.0 \%)$ of the examined I. persulcatus ticks (Tables 3 and 4). The prevalence of B. burgdorferi (s.l.) in I. pavlovskyi ticks from the Republic of Altai and Novosibirsk Province did not significantly differ (46.8\%; 95\% CI: 38.2-55.5 and 41.5\%; 95\% CI: 37.1-46.1, respectively) and was similar to that of $I$. persulcatus ticks from the same regions (37.8\%; 95\% CI: $31.2-45.0$ and 37.6\%; 95\% CI: 30.0-45.6, respectively). In two of the Novosibirsk sites (sites $\mathrm{N} 2$ and N5), the prevalence rates of $B$. burgdorferi (s.l.) in I. pavlovskyi ticks were lower, 22.7 and $14.3 \%$, respectively, than in other sites (Table 3 ). However, the samples from these sites were small.

Among spirochetes of the B. burgdorferi (s.l.) complex, four Borrelia species were identified in this study: $B$. afzelii, B. bavariensis, B. garinii and B. valaisiana (Table 5). In total, including cases of mixed infection, $B$. afzelii was detected in 1.4\% (8/577; 95\% CI: 0.7-2.7) of $I$. pavlovskyi ticks and in 11.7\% (39/334; 95\% CI: 8.7-15.6) of $I$. persulcatus ticks; $B$. bavariensis was revealed in $1.0 \%$ (6/577; 95\% CI: 0.5-2.3) of I. pavlovskyi ticks and in $23.4 \%(78 / 334 ; 95 \%$ CI: 19.1-28.2) of I. persulcatus ticks; B. garinii was found in 40.6\% (234/577; 95\% CI: $38.2-46.2)$ of I. pavlovskyi ticks and in 5.4\% (18/334; 95\% CI: 3.4-8.4) of I. persulcatus ticks (Table 4). Notably, this was the first discovery of $B$. bavariensis in I. pavlovskyi ticks, and all cases were recorded in Novosibirsk Province. Apparently, B. afzelii and $B$. bavariensis were detected significantly less often $\left(\chi^{2}=\right.$ 45.780, $d f=1, P<0.001$ and $\chi^{2}=125.853, d f=1, P<0.001$, respectively) in $I$. pavlovskyi ticks than in $I$. persulcatus ticks (Tables 4 and 5). By contrast, the prevalence of $B$. garinii in $I$. pavlovskyi ticks collected in the Republic of Altai and Novosibirsk Province (45.2\%; 95\% CI: 36.7-53.9 and 39.3\%; 95\% CI: 34.9-43.9, respectively) was significantly higher $\left(\chi^{2}=39.983, d f=1, P<0.001\right.$, for Altai, and $\chi^{2}=64.197, d f=1, P<0.001$, for Novosibirsk Province) than that in I. persulcatus ticks caught in the same regions (2.7\%; 95\% CI: 1.2-6.2 and 8.7\%; 95\% CI: 5.2-14.4, respectively) (Table 4). Borrelia valaisiana was not found in I. pavlovskyi ticks and was detected in only one $I$. persulcatus tick caught near Novosibirsk, which is the first finding of this bacterium in Novosibirsk Province (Table 5).

The determined $c l p A$ gene sequences of $B$. afzelii found in both I. pavlovskyi and I. persulcatus ticks (KX980208KX980214) were identical to known alleles deposited in the Borrelia MLST website (http://pubmlst.org/borrelia/) (Fig. 4). Only known $c l p A$ gene allele (KX980215) belonging to B. bavariensis was found in I. pavlovskyi ticks, while five new (KX980228-KX980232) and nine known (KX980216-KX980227) alleles were recorded in I. persulcatus ticks from both the Altai and Novosibirsk regions. Nine new $\operatorname{clp} A$ gene alleles of $B$. garinii were found in $I$. pavlovskyi ticks (KX980257-KX980268) and two new clpA gene alleles were identified in both $I$. pavlovskyi and I. persulcatus ticks (KX980253-KX980256, KX980272KX980273). In addition, ten known $c l p A$ gene alleles of $B$. garinii were recorded in I. pavlovskyi ticks (KX980236KX980252), and two known $\operatorname{clpA}$ gene alleles of B. garinii were found in both I. pavlovskyi and I. persulcatus ticks (KX980233-KX980235, KX980269-KX980271). A single clpA gene sequence belonging to B. valaisiana (KX980274) was identical to a previously published sequence (Fig. 4) that was detected in an I. persulcatus tick caught in Tomsk Province (Western Siberia) [77].

Analysis of the sequenced $p 83 / 100$ gene fragments of $B$. burgdorferi (s.l.) revealed six genetic variants of $B$. afzelii, 21 genetic variants of $B$. bavariensis, and 19 genetic variants of B. garinii (Fig. 5). Among them, three variants of $B$. afzelii (KX980285-KX980287), 15 variants of B. bavariensis (KX980289, KX980299-KX980313), and 14 variants of B. garinii (KX980324-KX980342, KX980346-KX980349) were new, while the other genetic variants were previously observed in I. persulcatus ticks [78]. Of the new genetic variants, 11 variants of B. garinii (KX980328-KX980342) were identified in I. pavlovskyi ticks (both in the Altai and Novosibirsk regions); while three variants of $B$. afzelii (KX980285-KX980287), 14 variants of $B$. bavariensis (KX980300-KX980313), and one variant of B. garinii (KX980348-KX980349) were identified in I. persulcatus ticks. In addition, a new variant of $B$. bavariensis (KX980289, KX980299) and two new variants of B. garinii (KX980324-KX980327, KX980346-KX980347) were identified in both tick species. Notably, one new $p 83 / 100$ genetic variant belonging to $B$. garinii that was only found in $I$. pavlovskyi ticks collected in both the Republic of Altai and Novosibirsk Province (KX980338-KX980339) was unusual and included a $36 \mathrm{bp}$ insertion. In addition, a genetic variant of the $B$. bavariensis p83/100 gene with a 3 bp insertion (KX980306) was identified in one I. persulcatus tick from Novosibirsk Province (Fig. 5).

The prevalence of B. miyamotoi in I. pavlovskyi and $I$. persulcatus ticks collected both in the Republic of Altai and Novosibirsk Province was similar, 6.4\% (37/577; 95\% CI: 4.7-8.7) and 6.3\% (21/334; 95\% CI: 4.2-9.4), respectively. The sequences of all determined $g l p Q$ gene fragments of B. miyamotoi detected in I. pavlovskyi and I. persulcatus ticks from both regions (KY006159-KY006162) were identical to each other and to a corresponding sequence of Asian-type B. miyamotoi [79], which was previously identified in I. persulcatus ticks from Novosibirsk Province (FJ940729) (Fig. 6).

\section{Detection and genotyping of Rickettsia spp.}

Rickettsia spp. were found in 8.1\% (47/577; 95\% CI: 6.2-10.7) of the examined $I$. pavlovskyi ticks and $77.5 \%(259 / 334 ; 95 \%$ CI: $72.8-81.7)$ of $I$. persulcatus 


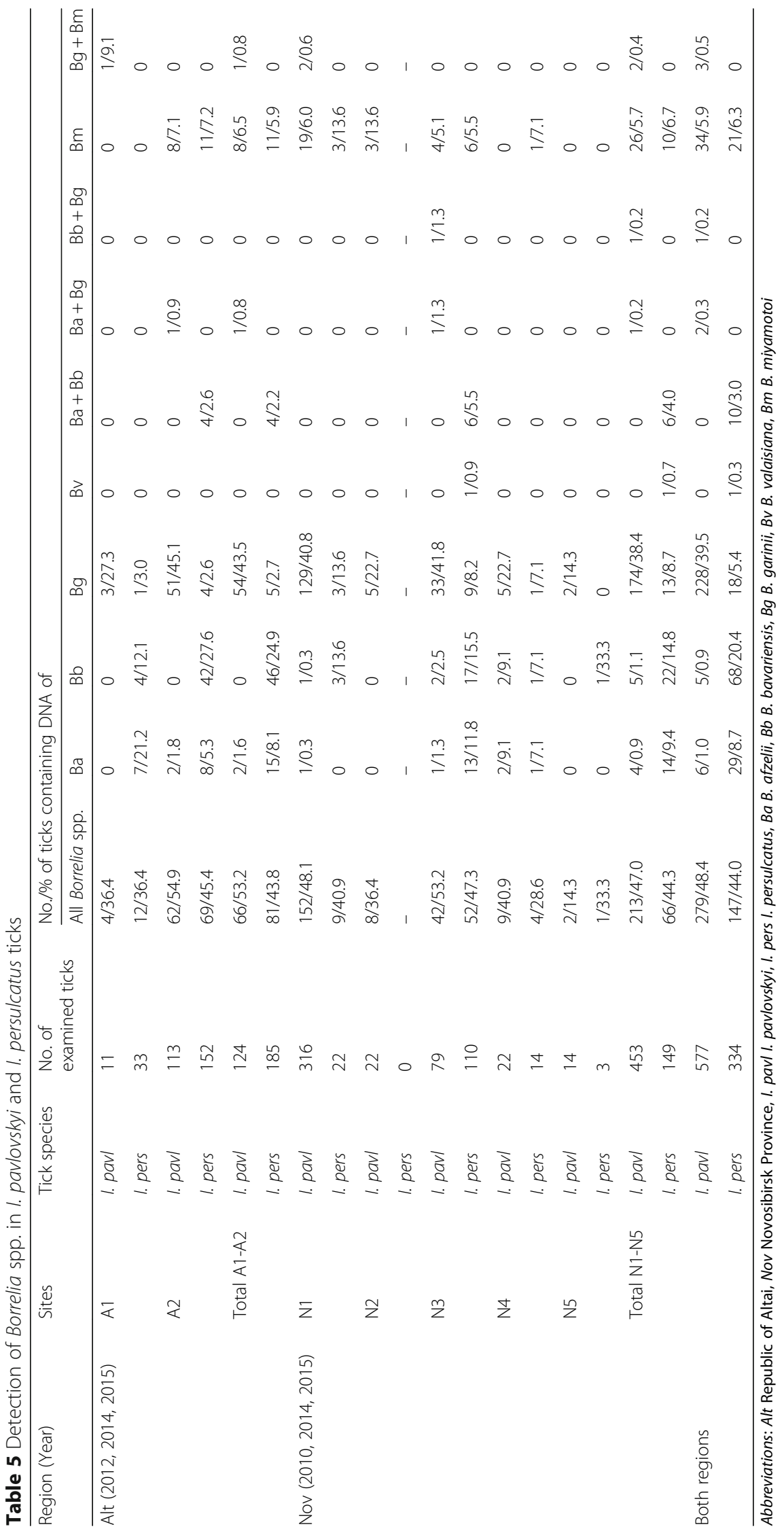




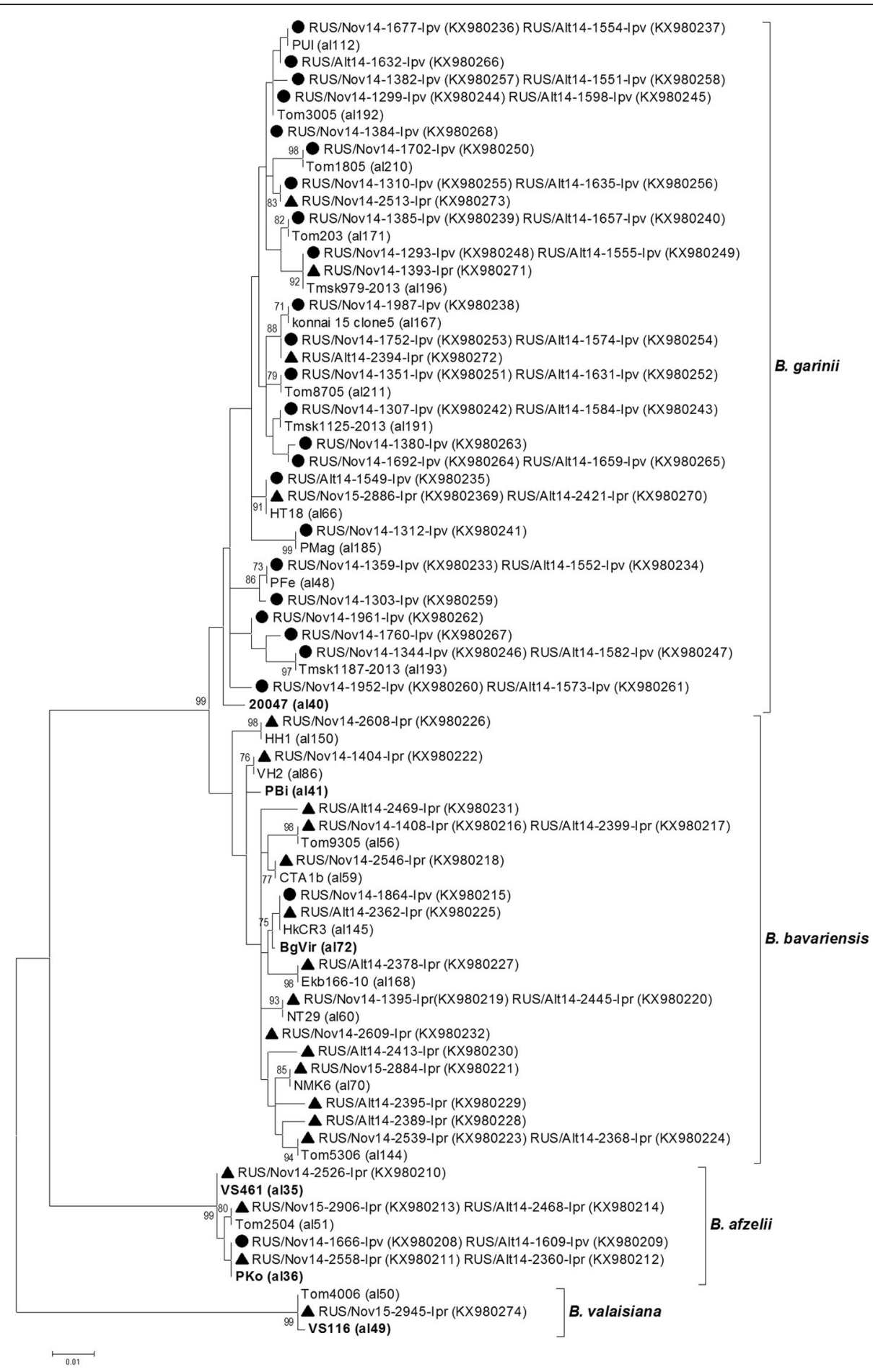

Fig. 4 The phylogenetic tree constructed by the ML method based on nucleotide sequences of 579 bp fragment of the clpA gene of Borrelia spp. from Borrelia burgdorferi (s.l.) complex. The scale-bar indicates an evolutionary distance of 0.01 nucleotides per position in the sequence. Significant bootstrap values (>70\%) are shown on the nodes. The sequences of prototype strains of Borrelia spp. from the Borrelia MLST website are in boldface. Legend: $\bullet$ I. pavlovskyi ticks; $\boldsymbol{\Delta}$ I. persulcatus ticks

ticks (Tables 3 and 4). In both regions, I. pavlovskyi ticks were infected with the Rickettsia spp. significantly less often $(8.9$ and $7.9 \%$ of infected individuals collected in the Republic of Altai and Novosibirsk suburbs, respectively) than $I$. persulcatus, in which the DNA of Rickettsia spp. was detected in $87.6 \%$ of 


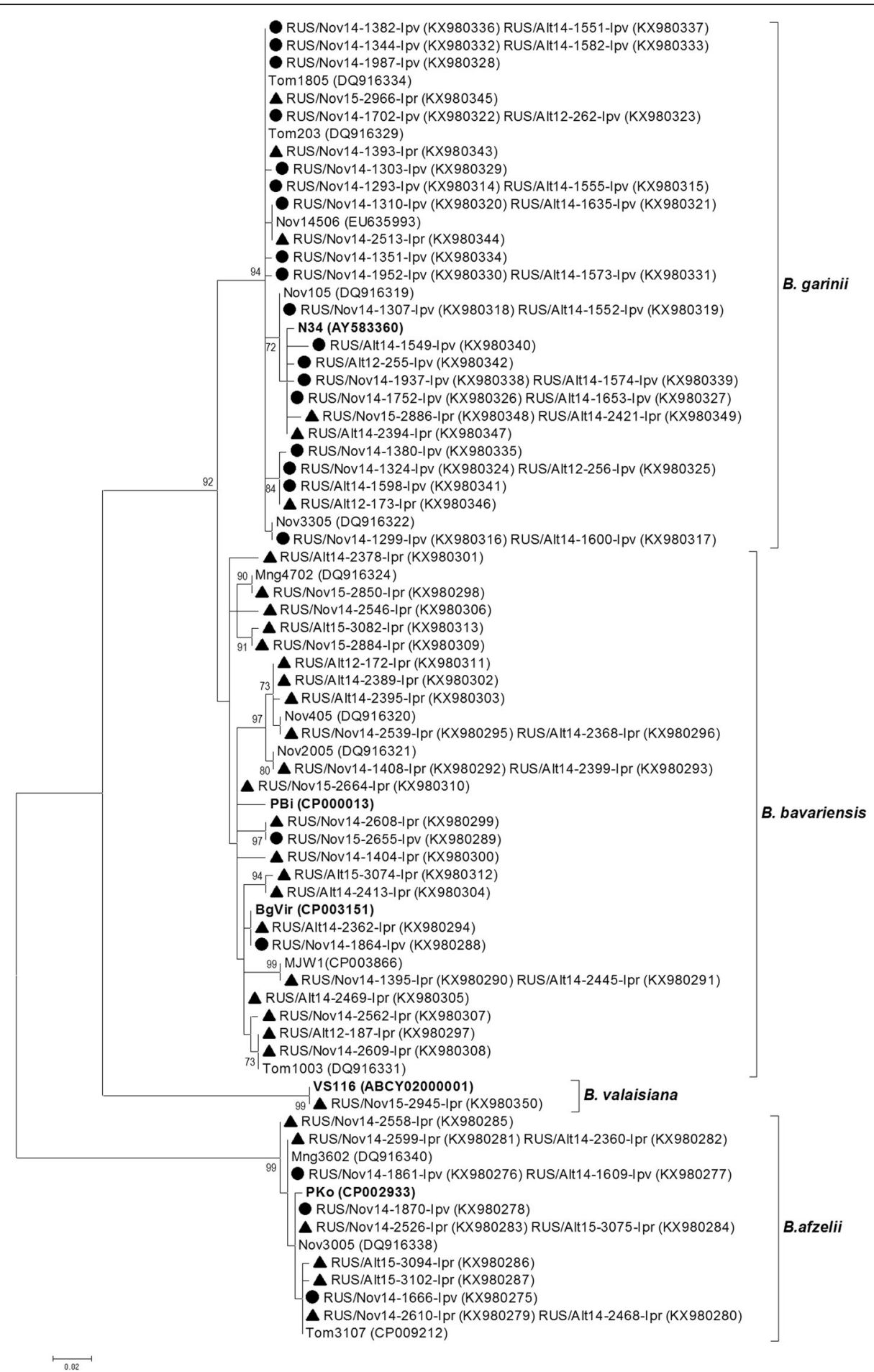

Fig. 5 The phylogenetic tree constructed by the ML method based on nucleotide sequences of 276-402 bp fragment of the $p 83 / 100$ gene of Borrelia spp. from Borrelia burgdorferi (s.l.) complex. The scale-bar indicates an evolutionary distance of 0.02 nucleotides per position in the sequence. Significant bootstrap values (>70\%) are shown on the nodes. The sequences of prototype strains of Borrelia spp. from GenBank database are in boldface. Legend: $\bullet$ I. pavlovskyi ticks; $\boldsymbol{\Delta}$ I. persulcatus ticks 


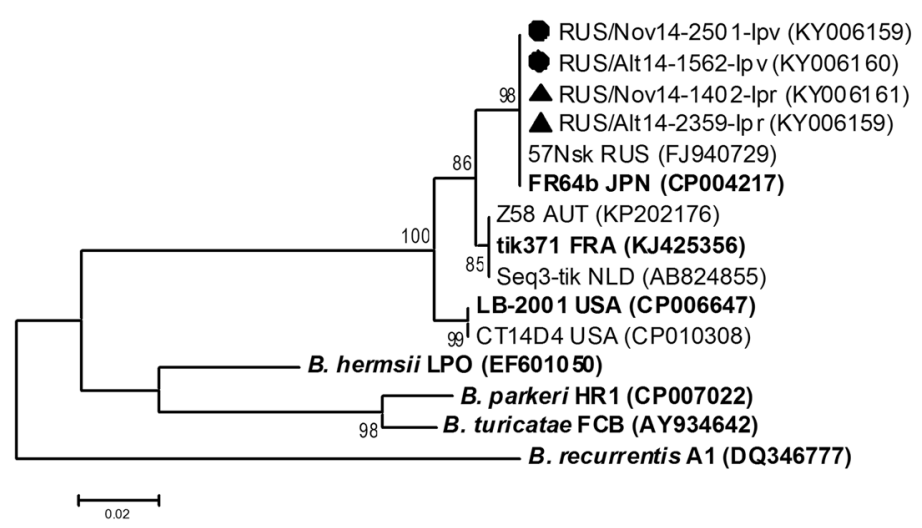

\section{B. miyamotoi}

Fig. 6 The phylogenetic tree constructed by the ML method based on nucleotide sequences of 359 bp fragment of the glpQ gene of Borrelia spp. from relapsing fever group. The scale-bar indicates an evolutionary distance of 0.02 nucleotides per position in the sequence. Significant bootstrap values (>70\%) are shown on the nodes. The sequences of prototype strains of Borrelia spp. from GenBank database are in boldface. Legend: $\bullet$ I. pavlovskyi ticks; $\boldsymbol{\Delta}$ I. persulcatus ticks

the samples from Altai and in $65.1 \%$ of the samples from Novosibirsk Province $\left(\chi^{2}=456.746, d f=1, P<\right.$ 0.001) (Table 4). Significant differences were observed in all studied sites with the exception of Sites N2 and N5, where the total number of collected Ixodes ticks was low.

Five Rickettsia species were identified and confirmed by sequencing: $R$. heilongiangensis, $R$. helvetica, $R$. raoultii, $R$. sibirica and "Ca. R. tarasevichiae", as well as two Rickettsia genetic variants that had not been previously found (Table 6). Notably, this is the first report of $R$. heilongjiangensis, $R$. helvetica, $R$. raoultii and "Ca. R. tarasevichiae" detection in I. pavlovskyi ticks. Distribution of several Rickettsia species varied between $I$. pavlovskyi and I. persulcatus ticks. Including cases of mixed infection, $R$. heilongjiangensis was found in $0.9 \%(5 / 577 ; 95 \%$ CI: $0.4-2.0)$ of I. pavlovskyi ticks and $0.3 \%(1 / 334 ; 95 \%$ CI: $0.1-1.7)$ of I. persulcatus ticks; $R$. helvetica was detected in 3.5\% (20/577; 95\% CI: 2.3-5.3) of I. pavlovskyi ticks and in $0.3 \%$ (1/334; 95\% CI: 0.1-1.7) of $I$. persulcatus ticks; $R$. raoultii was identified in $2.6 \%(15 / 577 ; 95 \% \mathrm{CI}: 1.6-4.2)$ of $I$. pavlovskyi ticks and in 6.0\% (20/334; 95\% CI: 3.9-9.1) of $I$. persulcatus ticks; and "Ca. R. tarasevichiae" was recorded in $1.7 \%(10 / 577 ; 95 \% \mathrm{CI}: 0.9-3.2)$ of $I$. pavlovskyi ticks and in $75.7 \%$ (253/334; 95\% CI: $70.1-$ 80.0 ) of $I$. persulcatus ticks (Tables 4 and 6). In addition, $R$. sibirica and new Rickettsia genetic variants were only found in $2.4 \%(8 / 334)$ and $0.6 \%$ (2/ 334) of I. persulcatus ticks, respectively. Thus, I. pavlovskyi ticks were significantly less often infected by " $\mathrm{Ca}$. R. tarasevichiae" compared to $I$. persulcatus ticks $\left(\chi^{2}=564.357\right.$, $d f=1, P<0.001$ ) (Table 4), and significant differences were observed in all studied sites, with the exception of Sites $\mathrm{N} 2$ and N5, where small amounts of Ixodes ticks were collected. In addition, I. pavlovskyi ticks were significantly more often infected by $R$. helvetica $\left(\chi^{2}=9.420, d f=1\right.$, $P=0.002)$; however, the significant difference was only observed in the Altai region $\left(\chi^{2}=15.481, d f=1, P<0.001\right)$ and not in Novosibirsk Province. The $R$. raoultii species was not found in I. pavlovskyi ticks from the Altai region; however, it was detected in both Ixodes species in Novosibirsk Province, though the prevalence of $R$. raoultii between these two tick species did not vary significantly $\left(\chi^{2}=0.612, d f=1, P=0.434\right)$. The prevalence of other Rickettsia species was too low for reliable comparisons (Tables 4 and 6).

Most of the identified gltA gene sequences (Fig. 7) of $R$. heilongjiangensis (KX963401-KX963403), R. helvetica (KX963385-KX963387), and "Ca. R. tarasevichiae" (KX963381-KX963384) found in both I. pavlovskyi and I. persulcatus ticks were identical to corresponding sequences previously found in $I$. persulcatus ticks (CP002912, RHU59723 and AF503167, respectively). Only single gltA gene sequences of $R$. heilongiangensis (KX963404) and R. helvetica (KX963388) detected in $I$. pavlovskyi ticks from the Novosibirsk Province and Altai Mountains, respectively, differed from the known corresponding sequences by 1-2 nucleotide substitutions (Fig. 7). Sequences of glt $A$ gene fragments belonging to $R$. raoultii detected in I. pavlovskyi ticks (KY019068, KY056616, KY056617) were identical to known corresponding sequences of genetic variants previously named RpA4 and DnS14 (DQ365803 and AF120028, respectively) or differed from DnS14 by a single nucleotide substitution (KY019068, KY056618). Rickettsia raoultii gltA gene fragments from $I$. persulcatus ticks (KX963389-KX963395) were more variable and belonged to the RpA4, DnS14, and DnS28 genetic variants (AF120028, DQ365803 and AF120027, respectively) or differed from them by 1-3 nucleotide substitutions (KX963391-KX963394). The determined gltA gene sequences of $R$. sibirica found in $I$. 


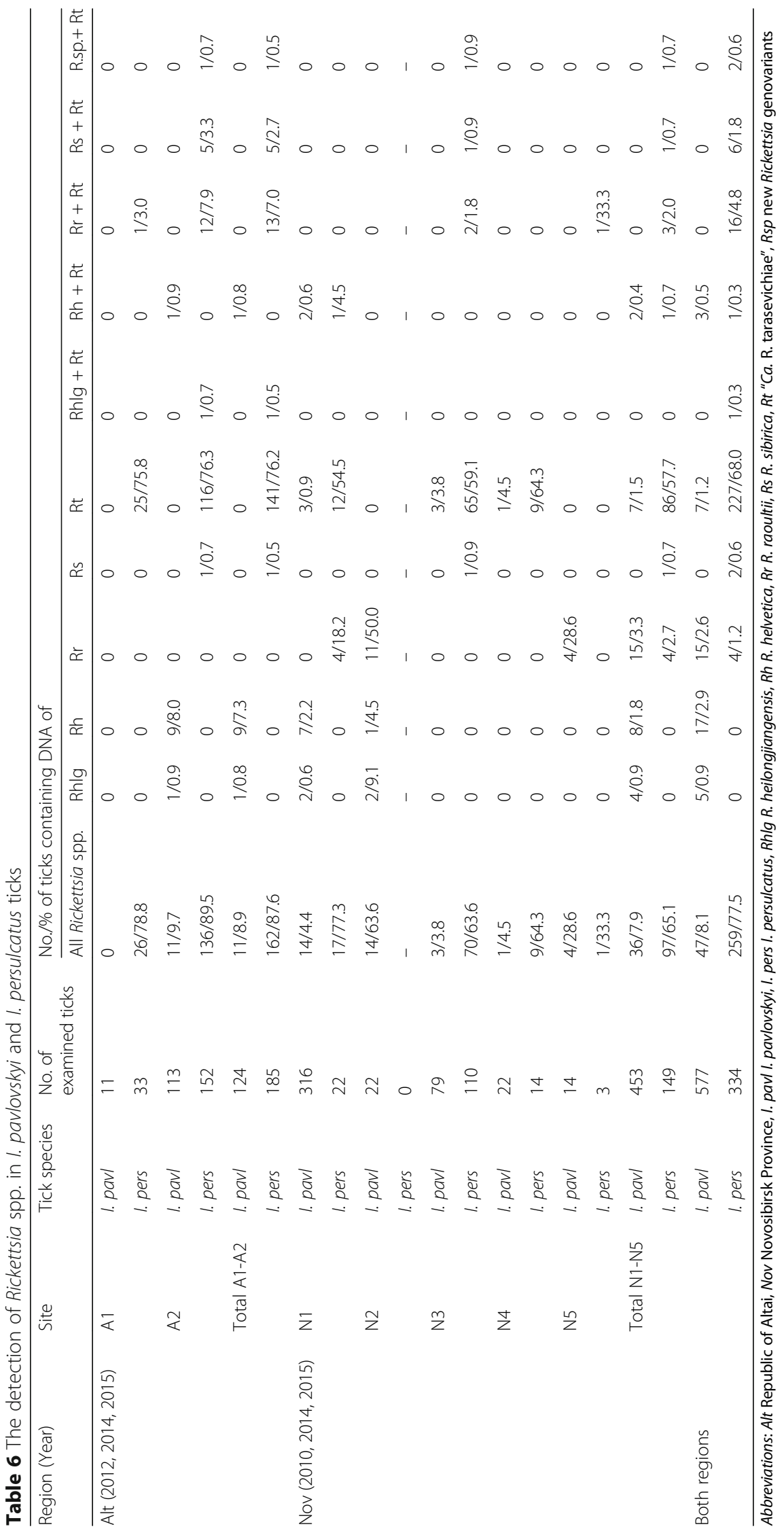




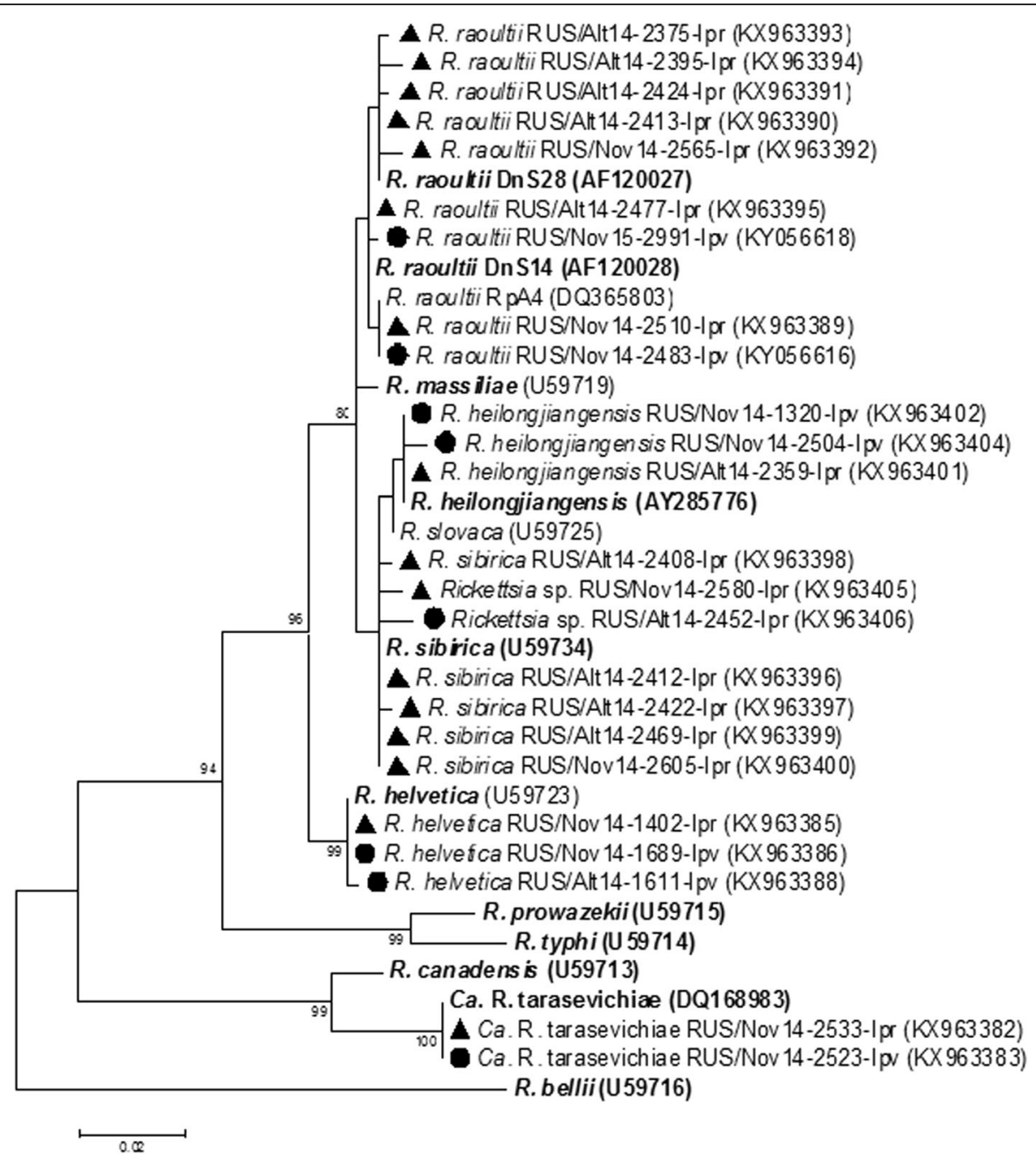

Fig. 7 The phylogenetic tree constructed by the ML method based on nucleotide sequences of 474 bp fragment of the gltA gene of Rickettsia spp. The scale-bar indicates an evolutionary distance of 0.02 nucleotides per position in the sequence. Significant bootstrap values (>75\%) are shown on the nodes. The sequences of prototype strains of Rickettsia spp. from GenBank database are in boldface. Legend: $\bullet$ I. pavlovskyi ticks; A I. persulcatus ticks

persulcatus ticks from both the Altai and Novosibirsk regions (KX963396-KX963400, KY019069) were identical to a known sequence of $R$. sibirica (RSU59734) or differed from it by 1-2 nucleotide substitutions (KX963397, KX963398, KX963400, KY019069). The sequences of the two new Rickettsia spp. isolates (KX963405, KX963406) were most similar to the R. sibirica sequence (RSU59734), but differed from it by 4-5 nucleotide substitutions (Fig. 7).

\section{Detection and genotyping of Anaplasmataceae bacteria} Bacteria of three species belonging to the family Anaplasmataceae were identified in both I. pavlovskyi and I. persulcatus ticks: A. phagocytophilum, E. muris and "Ca. N. mikurensis". In both the Altai and Novosibirsk regions, A. phagocytophilum was found in 3.3\% (19/577;
95\% CI: 2.1-5.1) of I. pavlovskyi ticks and in 6.3\% (21/334; 95\% CI: 4.2-9.4) of I. persulcatus ticks; E. muris was detected in $0.3 \%(2 / 577$; 95\% CI: $0.1-1.3)$ of I. pavlovskyi ticks and in 12.0\% (40/334; 95\% CI: 8.9-15.9) of $I$. persulcatus ticks; "Ca. N. mikurensis" was identified in $1.6 \%(9 / 577 ; 95 \%$ CI: $0.8-2.9)$ of I. pavlovskyi ticks and in $0.6 \%(2 / 334 ; 95 \%$ CI: $0.2-2.2)$ of $I$. persulcatus ticks (Tables 3 and 4). Thus, A. phagocytophilum, E. muris and "Ca. N. mikurensis" were discovered in $I$. pavlovskyi ticks for the first time, although E. muris DNA was detected in single individuals of this tick species, one each from the Altai and Novosibirsk regions. In both regions, I. pavlovskyi ticks were significantly less often infected by $E$. muris $\left(\chi^{2}=65.056\right.$, $d f=1, \quad P<0.001)$ compared to $I$. persulcatus ticks (Table 4). For A. phagocytophilum and "Ca. N. mikurensis", 
there was no significant difference in their prevalence between I. pavlovskyi and I. persulcatus ticks.

Two sequence variants of the A. phagocytophilum groESL operon were revealed in both I. pavlovskyi and I. persulcatus ticks (KX980041-KX980043 and KX980044KX980046, respectively); these sequences corresponded to two distinct genetic groups of $A$. phagocytophilum that were previously identified in I. persulcatus ticks in Russia (HM366570 and HM366569, respectively) [80] (Fig. 8). The determined groESL operon sequences of E. muris (KX980047-KX980049) corresponded to sequences that were previously found in I. persulcatus ticks in Russia (GU358686 and GU358687). Along with these sequences, one new groESL operon sequence variant (KX980048) was detected in an I. persulcatus tick from Altai. The "Ca. N. mikurensis" sequences of the groESL operon detected in $I$. pavlovskyi ticks were highly conserved (KX980039 and KX980040) and identical to sequences previously found in I. persulcatus ticks in Russia (FJ966361) (Fig. 8).

\section{Detection and genotyping of Babesia spp.}

Babesia DNA was found only in four ticks, including two I. pavlovskyi ticks from the Republic of Altai and two I. persulcatus ticks from Novosibirsk Province (Table 3). The determined 18S rRNA gene fragment sequences of Babesia sp. found in both tick species (KX987863 and KX987864, respectively) were identical to corresponding sequences of US-type Bab. microti previously identified in I. persulcatus ticks collected in the Far-Eastern and Siberian parts of Russia (GU057384, GU057383) (Fig. 9). Notably, this was the first finding of Bab. microti in I. pavlovskyi ticks.

\section{Discussion}

Ixodes pavlovskyi ticks are known to be closely related to I. persulcatus $[54,58]$ and, as expected, the same infectious agents could be vectored by $I$. pavlovskyi. Indeed, several human pathogens have been detected in this tick species [36, 48, 51, 66, 67]; however, thorough investigations of the ability of I. pavlovskyi ticks to transmit a wide range of pathogens have not been conducted. In this study, the prevalence and genetic diversity of TBEV, KEMV, B. burgdorferi (s.l.), B. miyamotoi, Rickettsia spp., Anaplasmataceae bacteria and Babesia spp. were investigated in I. pavlovskyi ticks and compared with those in I. persulcatus.

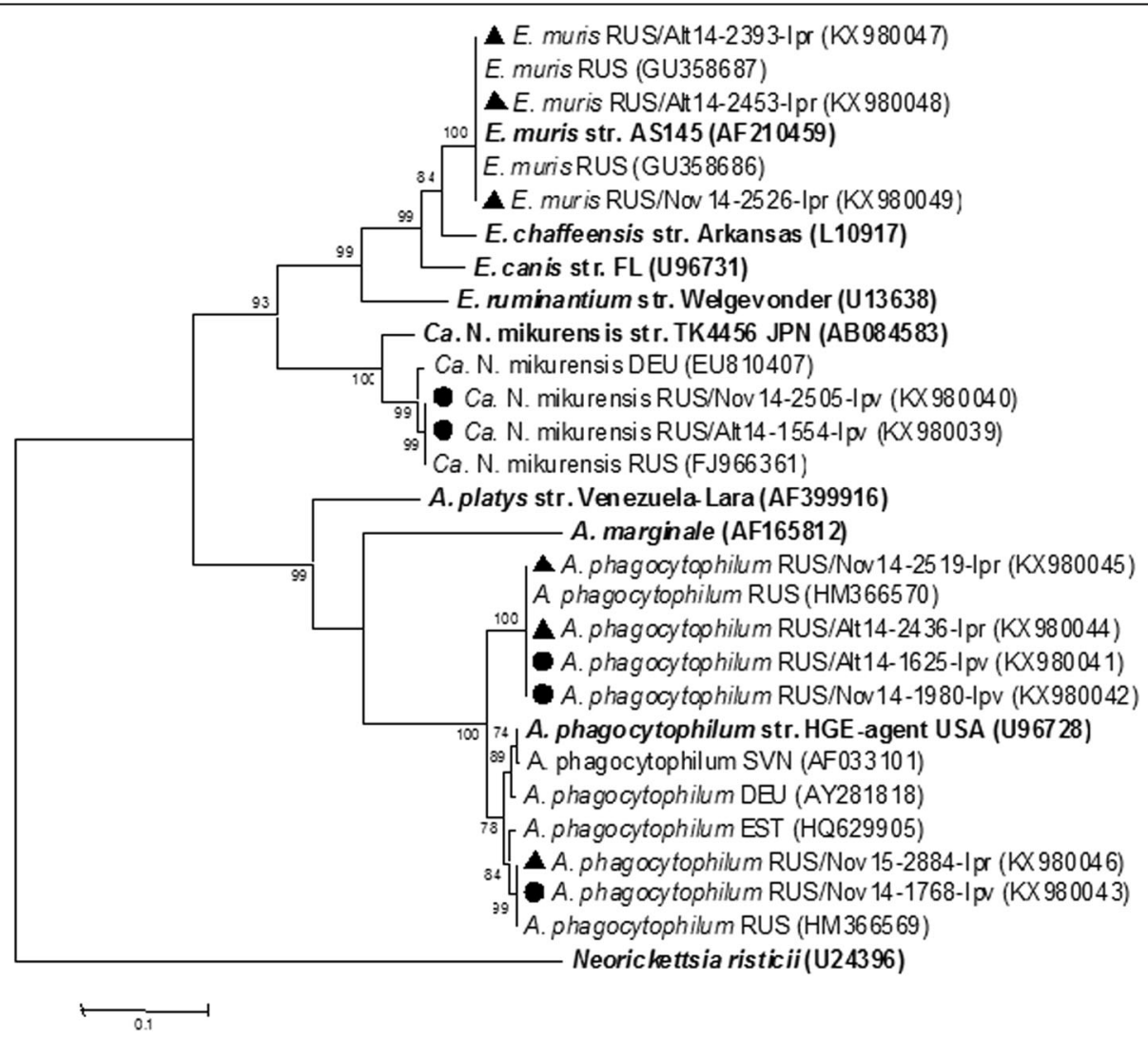

Fig. 8 The phylogenetic tree constructed by the ML method based on nucleotide sequences of 1166-1174 bp fragment of the groESL operon of Anaplasmataceae bacteria. The scale-bar indicates an evolutionary distance of 0.1 nucleotides per position in the sequence. Significant bootstrap values (>75\%) are shown on the nodes. The sequences of prototype strains of Anaplasmataceae bacteria from GenBank database are in boldface. Legend: $\bullet$ I. pavlovskyi ticks; $\Delta$ I. persulcatus ticks 


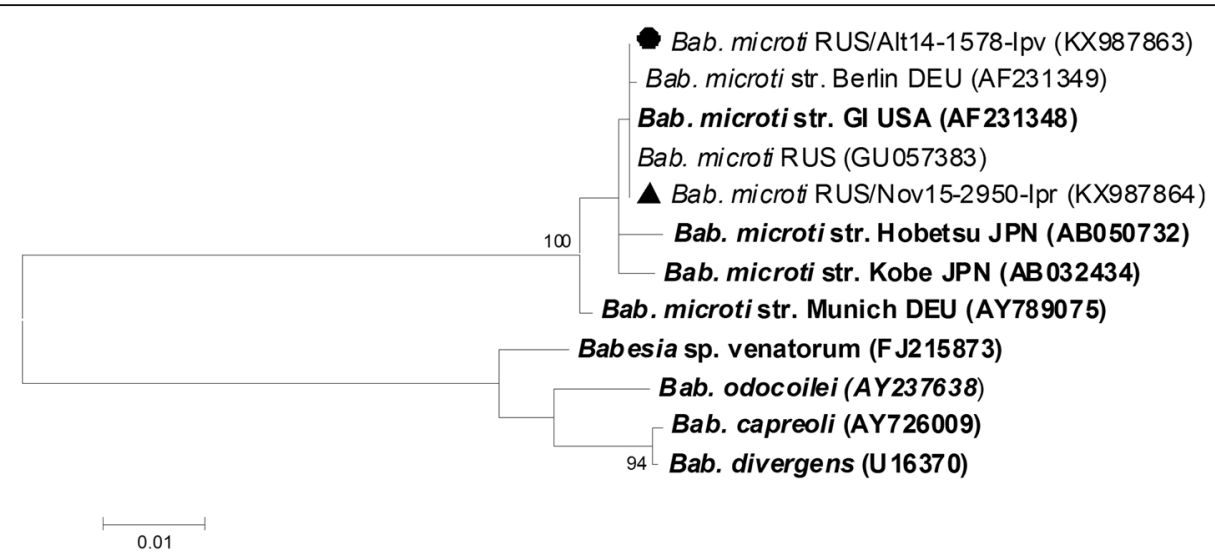

Fig. 9 The phylogenetic tree constructed by the ML method based on nucleotide sequences of 1160-1200 bp fragment of the 18S rRNA gene of Babesia spp. The scale-bar indicates an evolutionary distance of 0.01 nucleotides per position in the sequence. Significant bootstrap values (>75\%) are shown on the nodes. The sequences of prototype strains of Babesia spp. from GenBank database are in boldface. Legend: • I. pavlovskyi ticks; A I. persulcatus ticks

Ixodes pavlovskyi and I. persulcatus were collected in two geographically distant regions where these tick species occur in sympatry: the northern part of the Altai Mountains and suburbs of Novosibirsk. Both regions are located within the Western Siberian part of the $I$. pavlovskyi disjunctive distribution area. The Altai Mountains area is the traditional habitat of this tick species, and I. pavlovskyi ticks have been regularly detected in this region, with the proportion ranging from 0.1 to $40 \%$ in different sites $[38,55,58,81]$. In the suburbs of Novosibirsk, I. pavlovskyi ticks became more abundant only during this century and their proportion among the captured ticks varied from 3 to $94 \%$ in different locations $[35,58,62]$. Notably, the existence of I. pavlovskyi/I. persulcatus natural hybrids was previously shown [61]. To exclude possible hybrids, each adult tick was characterized using both morphological and genetic criteria, and all intermediate morphological forms and genetic crosses were excluded from this study. Unexpectedly, the occurrence of $I$. pavlovskyi ticks in the Novosibirsk suburbs was significantly higher than in the Altai Mountains, its traditional habitat area. This difference could be associated with peculiarities of the I. pavlovskyi and $I$. persulcatus life-cycles: adult I. pavlovskyi ticks feed mainly on birds, while I. persulcatus ticks feed on medium-sized and large mammals. Therefore, the considerable anthropogenic influence observed in the suburbs of Novosibirsk, a city of more than 1.5 million people, resulted in a substantial decrease of mediumsized and large mammals in this area that might contribute to the significantly lower $I$. persulcatus share of this tick population.

Despite the aforementioned differences in the lifecycles of I. pavlovskyi and I. persulcatus ticks, they have a similar ecology and overlapping activity periods, and their immature stages feed on the same small mammals. As a result, I. pavlovskyi and I. persulcatus larvae and nymphs can acquire the same infectious agents by feeding on infected mammals or by co-feeding with infected ticks, and these tick species can therefore transmit similar repertoires of pathogens.

Indeed, almost the full spectrum of tested infectious agents was identified in $I$. pavlovskyi ticks, including $B$. bavariensis, $R$. heilongjiangensis, R. helvetica, R. raoultii, "Ca. R. tarasevichiae", A. phagocytophilum, E. muris, "Ca. N. mikurensis" and Bab. microti, which were found in this tick species for the first time (Table 3). The exceptions were $R$. sibirica and B. valaisiana, which were not identified in I. pavlovskyi ticks collected in either the Altai Mountains or the Novosibirsk suburbs. Notably, $B$. valaisiana is extremely rare in the Asian part of Russia $[77,82]$ and the B. valaisiana isolate detected in $I$. persulcatus in this study was only the second isolate found in Western Siberia. The prevalence of a number of infectious agents, including TBEV, KEMV, B. miyamotoi, A. phagocytophilum, "Ca. N. mikurensis", and Bab. microti, was similar in both I. pavlovskyi and I. persulcatus ticks. Moreover, we could not identify specific genetic variants of these agents associated with only one of these two tick species. However, the distribution of some bacterial species belonging to the B. burgdorferi (s.l.) complex, genus Rickettsia, and family Anaplasmataceae significantly varied in the studied tick species.

Among spirochetes of the B. burgdorferi (s.l.) complex, B. garinii was significantly more often found in $I$. pavlovskyi, while B. bavariensis and B. afzelii were significantly more prevalent in $I$. persulcatus ticks (Tables 4 and 5). These data correspond to the results of other investigators, which demonstrated the presence of B. garinii only in I. pavlovskyi ticks [51]. Moreover, 
many new genetic variants of $B$. garinii, according to the clpA and p83/100 gene sequences, were detected in $I$. pavlovskyi ticks collected from both the Altai Mountains and Novosibirsk suburbs and further investigations based on MLST are required for the genetic characterization of Borrelia spp. in I. pavlovskyi ticks. In spite of such differences in the Borrelia spp. distribution in these tick species, the total average prevalence of spirochetes of the B. burgdorferi (s.l.) complex in I. pavlovskyi and I. persulcatus ticks did not significantly differ in either the Altai Mountains or Novosibirsk suburbs (Table 4).

As for Rickettsia species, I. pavlovskyi ticks were shown to carry the same Rickettsia species as I. persulcatus, except $R$. sibirica. However, I. pavlovskyi ticks were infected with Rickettsia spp. significantly less often than I. persulcatus (8.1 vs $77.5 \%$ ), and significant differences were observed in both the Altai Mountains and Novosibirsk suburbs (Tables 4 and 6). In I. persulcatus ticks, "Ca. R. tarasevichiae" is known to be a predominant Rickettsia species and was identified in $45-90 \%$ of individuals collected in most of the examined regions. $R$. heilongjiangensis, $R$. helvetica, $R$. raoultii and $R$. sibirica are substantially rarer species of Rickettsia [15, 40, 49, 50]. Surprisingly, I. pavlovskyi ticks were significantly less often infected by "Ca. R. tarasevichiae" $(<2 \%)$ and more often infected by $R$. helvetica compared to $I$. persulcatus (Tables 4 and 6). Despite variations in the distribution of Rickettsia species in I. pavlovskyi and I. persulcatus ticks, most genetic variant of "Ca. R. tarasevichiae", R. helvetica and $R$. heilongjiangensis were common for both tick species, while several new genetic variants of $R$. raoultii were found in $I$. pavlovskyi and I. persulcatus ticks (Fig. 7). In addition, two new genetic variants of $R$. sibirica and two new genetic variants of Rickettsia spp. related to $R$. sibirica were found in $I$. persulcatus ticks. Further sequencing of other genetic loci of these unusual isolates is required.

From bacteria belonging to the Anaplasmataceae family, monocytic $E$. muris was only detected in two $I$. pavlovskyi ticks, which was significantly rarer compared to I. persulcatus ticks (Tables 3 and 4). Previously, this bacterium was found in different tick species in Eurasia, including Haemaphysalis flava, I. ricinus and I. persulcatus $[12,15,45,83]$. Therefore, a significant difference in its prevalence in the closely related I. pavlovskyi and $I$. persulcatus was unexpected.

Notably, in addition to the Siberian subtype of TBEV, which is common in these regions, a TBEV of European subtype and a putative new subtype, 886-84, were first detected in $I$. pavlovskyi ticks in this study (Fig. 2). Moreover, TBEV strains belonging to the 886-84 group (EF469662, KJ633033) were previously found only in Eastern Siberia and Mongolia [33, 76], approximately $1400-1700 \mathrm{~km}$ away from the suburbs of Novosibirsk, and our findings could reflect a possibly wider distribution of this genetic variant of TBEV.

Interestingly, one unusual KEMV isolate was found in an I. pavlovskyi tick caught in the Novosibirsk suburbs (Fig. 3). Its segment 1 fragment sequence differed considerably from the corresponding sequences of other isolates found in Ixodes ticks collected in the northern part of the Altai Mountains in this study, a KEMV strain isolated from $I$. persulcatus ticks from Kemerovo Province (Western Siberia, Russia) in 1968, and a KEMV strain identified from a redstart, Phoenicurus ochruros, in Egypt in 1961 [84]. However, the data on KEMV are limited, as only two different sequences of the KEMV segment 1 fragment are currently available in the GenBank database, and more KEMV sequences are required to interpret these results.

Thus, a number of new genetic variants of $B$. garinii and single new variants of KEMV, $R$. heilongjiangensis, $R$. helvetica and $R$. raoultii were only found in I. pavlovskyi ticks in this study. Previously, the association of different genetic variants of several tick-transmitted infectious agents with particular Ixodes ticks has been shown: specific genetic lineages of $A$. phagocytophilum were identified in I. ricinus, I. persulcatus and I. trianguliceps [85-87] and distinct genotypes of Bab. microti, US-type and Hobetsu-type, were detected in I. persulcatus and I. ovatus, respectively [19]. Conventionally, different subtypes of TBEV and types of B. miyamotoi have been associated with $I$. ricinus and $I$. persulcatus ticks $[2,79,88]$ and single exceptions were found in the sympatric area of I. ricinus and I. persulcatus located in Estonia and Latvia [79, 89]. Moreover, viral determinants responsible for the association of European and Siberian subtypes of TBEV have recently been revealed [90]. However, our observation of new genetic variants of $B$. garinii only in $I$. pavlovskyi ticks does not allow us to conclude that these variants are associated with this tick species because data on the genetic diversity of B. burgdorferi (s.l.) in I. pavlovskyi ticks are limited, and further detailed examination is required.

\section{Conclusion}

In summary, the first detailed study of the prevalence and genetic characteristics of a wide range of infectious agents in I. pavlovskyi ticks demonstrated that almost all previously detected pathogens in $I$. persulcatus ticks can be found in $I$. pavlovskyi. Only B. valaisiana and $R$. sibirica were not found in the tested I. pavlovskyi ticks. For the first time, B. bavariensis, $R$. helvetica, $R$. heilongjiangensis, $R$. raoultii, "Ca. R. tarasevichiae”, A. phagocytophilum, E. muris, "Ca. N. mikurensis" and Bab. microti were identified in I. pavlovskyi ticks. For TBEV, KEMV, B. miyamotoi, A. phagocytophilum, "Ca. N. mikurensis", and Bab. microti, the prevalence and 
genetic variants were similar in both I. pavlovskyi and $I$. persulcatus ticks. However, the distribution of species belonging to the B. burgdorferi (s.l.) complex, Rickettsia genus and $E$. muris was different between tick species, and many new genetic variants of B. garinii and Rickettsia spp. were identified in I. pavlovskyi ticks. In total, $58 \%$ of I. pavlovskyi and $88 \%$ of I. persulcatus ticks were infected by at least one of the examined agents (Table 3). Ixodes pavlovskyi ticks were significantly less often infected by pathogens compared to I. persulcatus ticks, because of the low prevalence of "Ca. R. tarasevichiae" in this tick species. We can assume that the I. pavlovskyi/I. persulcatus sympatric areas might be characterized by a greater genetic diversity of infectious agents and pose a greater threat to public health compared to the $I$. persulcatus allopatric areas, but further investigations of natural I. pavlovskyi/I. persulcatus hybrids are required.

\section{Acknowledgments}

The authors would like to thank Mrs. Tamara Epikhina and Nina Melnikova for their technical assistance.

\section{Funding}

This study was supported by Russian Scientific Foundation, research project No. 15-14-20020.

\section{Availability of data and materials}

The datasets supporting the conclusions of this article are included within the article. The newly generated sequences are available in the GenBank database.

\section{Authors' contributions}

NT designed the study. NL, SL, AT, and VP participated in field work. NL, GK, and AT identified tick species. VR, ST, GK, YS, YI, and NF carried out molecular identification of infection agents. AT performed sequencing. VR, ST, YS, YI, AT, IB and NT performed data analysis and interpretation. VR and NT wrote the manuscript. All authors edited and approved the final manuscript.

\section{Authors' information}

Currently Nataliya Fomenko works at Join-stock company "Vector-Best", Novosibirsk, Russian Federation.

\section{Competing interests}

The authors declare that they have no competing interests.

\section{Consent for publication}

Not applicable.

\section{Ethics approval and consent to participate}

Not applicable.

\section{Publisher's Note}

Springer Nature remains neutral with regard to jurisdictional claims in published maps and institutional affiliations.

\section{Author details}

'Institute of Chemical Biology and Fundamental Medicine, SB RAS, Novosibirsk, Russian Federation. ${ }^{2}$ Institute of Systematics and Ecology of Animals SB RAS, Novosibirsk, Russian Federation.
Received: 9 November 2016 Accepted: 11 May 2017

Published online: 25 May 2017

\section{References}

1. Filippova NA. Ixodid ticks of the subfamily Ixodinae. Fauna of the USSR. Arachnida. Leningrad: Publishing House Nauka; 1977. (In Russian).

2. Gritsun TS, Lashkevich VA, Gould EA. Tick-borne encephalitis. Antiviral Res. 2003;57:129-46.

3. Korenberg El. Tick-borne encephalitis. In: Lvov DK, Klimenko SM, Gaidamovich CY, editors. Arboviruses and arboviral infections. Moscow: Meditsina; 1989. p. 256-64. (In Russian).

4. Parola P, Raoult D. Ticks and tickborne bacterial diseases in humans: an emerging infectious threat. Clin Infect Dis. 2001:32:897-928.

5. Korenberg El, Kovalevskii YV, Gorelova NB. Tick-host-Borrelia population interactions: long-term records in Eastern Europe. Exp Appl Acarol. 2002;28:225-9

6. Mansfield KL, Johnson N, Phipps LP, Stephenson JR, Fooks AR, Solomon T. Tick-borne encephalitis virus - a review of an emerging zoonosis. J Gen Virol. 2009;90(Pt 8):1781-94.

7. Rudenko N, Golovchenko M, Grubhoffer L, Oliver Jr JH. Updates on Borrelia burgdorferi sensu lato complex with respect to public health. Ticks Tick Borne Dis. 2011:2:123-8.

8. Dantas-Torres F, Chomel BB, Otranto D. Ticks and tick-borne diseases: a One Health perspective. Trends Parasitol. 2012;28:437-46.

9. Rizzoli A, Silaghi C, Obiegala A, Rudolf I, Hubálek Z, Földvári G, et al. Ixodes ricinus and its transmitted pathogens in urban and peri-urban areas in Europe: new hazards and relevance for public health. Front Public Health. 2014:2:251.

10. Nelder MP, Russell CB, Sheehan NJ, Sander B, Moore S, Li Y, et al. Human pathogens associated with the blacklegged tick Ixodes scapularis: a systematic review. Parasit Vectors. 2016;9:265.

11. Gern L, Rouvinez E, Toutoungi LN, Godfroid E. Transmission cycles of Borrelia burgdorferi sensu lato involving Ixodes ricinus and/or I. hexagonus ticks and the European hedgehog, Erinaceus europaeus, in surburban and urban areas in Switzerland. Folia Parasitol. 1997:44:309-14.

12. Kawahara M, Rikihisa Y, Isogai E, Takahashi M, Misumi H, Suto C, et al. Ultrastructure and phylogenetic analysis of 'Candidatus Neoehrlichia mikurensis' in the family Anaplasmataceae, isolated from wild rats and found in Ixodes ovatus ticks. Int I Syst Evol Microbiol. 2004;54:1837-43.

13. Dumler JS, Choi KS, Garcia-Garcia JC, Barat NS, Scorpio DG, Garyu JW, et al. Human granulocytic anaplasmosis and Anaplasma phagocytophilum. Emerg Infect Dis. 2005;11:1828-34.

14. Rar VA, Fomenko NV, Dobrotvorsky AK, Livanova NN, Rudakova SA, Fedorov EG, et al. Tickborne pathogen detection, Western Siberia, Russia. Emerg Infect Dis. 2005;11:1708-15.

15. Shpynov S, Fournier PE, Rudakov N, Tarasevich I, Raoult D. Detection of members of the genera Rickettsia, Anaplasma, and Ehrlichia in ticks collected in the Asiatic part of Russia. Ann NY Acad Sci. 2006;1078:378-83.

16. Masuzawa T, Kharitonenkov IG, Okamoto Y, Fukui T, Ohashi N. Prevalence of Anaplasma phagocytophilum and its coinfection with Borrelia afzelii in Ixodes ricinus and Ixodes persulcatus ticks inhabiting Tver Province (Russia) - a sympatric region for both tick species. J Med Microbiol. 2008:57(Pt 8):986-91.

17. Gray J, Zintl A, Hildebrandt A, Hunfeld KP, Weiss L. Zoonotic babesiosis: overview of the disease and novel aspects of pathogen identity. Ticks Tick Borne Dis. 2010;1:3-10.

18. Lane RS, Mun J, Peribáñez MA, Fedorova N. Differences in prevalence of Borrelia burgdorferi and Anaplasma spp. infection among host-seeking Dermacentor occidentalis, Ixodes pacificus, and Ornithodoros coriaceus ticks in northwestern California. Ticks Tick Borne Dis. 2010;1:159-67.

19. Zamoto-Niikura A, Tsuji M, Qiang W, Nakao M, Hirata H, Ishihara C. Detection of two zoonotic Babesia microti lineages, the Hobetsu and U.S. lineages, in two sympatric tick species, Ixodes ovatus and Ixodes persulcatus, respectively, in Japan. Appl Environ Microbiol. 2012;78:3424-30.

20. Kreizinger Z, Hornok S, Dán A, Hresko S, Makrai L, Magyar T, et al. Prevalence of Francisella tularensis and Francisella-like endosymbionts in the tick population of Hungary and the genetic variability of Francisella-like agents. Vector Borne Zoonotic Dis. 2013;13:160-3.

21. Nieto NC, Salkeld DJ. Epidemiology and genetic diversity of Anaplasma phagocytophilum in the San Francisco Bay area, California. Am J Trop Med Hyg. 2016;95:50-4. 
22. Silaghi C, Beck R, Oteo JA, Pfeffer M, Sprong H. Neoehrlichiosis: an emerging tick-borne zoonosis caused by Candidatus Neoehrlichia mikurensis. Exp Appl Acarol. 2016;68:279-97. doi:10.1007/s10493-015-9935-y.

23. Zintl A, Mulcahy G, Skerrett HE, Taylor SM, Gray JS. Babesia divergens, a bovine blood parasite of veterinary and zoonotic importance. Clin Microbiol Rev. 2003;16:622-36.

24. Woldehiwet Z. Anaplasma phagocytophilum in ruminants in Europe. Ann NY Acad Sci. 2006;1078:446-60.

25. Noureddine R, Chauvin A, Plantard O. Lack of genetic structure among Eurasian populations of the tick Ixodes ricinus contrasts with marked divergence from north-African populations. Int J Parasitol. 2011;41:183-92.

26. Mannelli A, Bertolotti L, Gern L, Gray J. Ecology of Borrelia burgdorferi sensu lato in Europe: transmission dynamics in multi-host systems, influence of molecular processes and effects of climate change. FEMS Microbiol Rev. 2012;36:837-61.

27. Van Zee J, Piesman JF, Hojgaard A, Black IV WC. Nuclear markers reveal predominantly North to South gene flow in Ixodes scapularis, the tick vector of the Lyme disease spirochete. Plos One. 2015;10:e0139630.

28. Gulia-Nuss M, Nuss AB, Meyer JM, Sonenshine DE, Roe RM, Waterhouse RM, et al. Genomic insights into the Ixodes scapularis tick vector of Lyme disease. Nat Commun. 2016;7:10507.

29. Sapegina VF, Dorontsova VA, Telegin VI, Ivleva NG, Dobrotvorskiy AK. The features of Ixodes persulcatus distribution in the forest area of Novosibirsk. Parazitologiya. 1985;19:370-3. (In Russian).

30. Alekseev AN, Burenkova LA, Chunikhin SP. The features of behavior of Ixodes persulcatus Sch. ticks, infected with tick-borne encephalitis. Med Parazitologiya. 1988;2:71-5. (In Russian).

31. Balashov YS. Ixodid ticks - parasites and vectors of infections. Leningrad: Nauka; 1998 (In Russian).

32. Bakhvalova VN, Rar VA, Tkachev SE, Matveev VA, Matveev LE, Karavanov AS, et al. Tickborne encephalitis virus strains of Western Siberia. Virus Res. 2000;70:1-12.

33. Demina TV, Dzhioev YP, Verkhozina MM, Kozlova IV, Tkachev SE, Plyusnin A, et al. Genotyping and characterization of the geographical distribution of tick-borne encephalitis virus variants with a set of molecular probes. J Med Virol. 2010;82:965-76.

34. Tkachev SE, Demina TV, Dzhioev YP, Kozlova IV, Verkhozina MM, Doroshchenko EK, et al. Genetic studies of tick-borne encephalitis virus strains from Western and Eastern Siberia. In: Rǔžek D, editor. Flavivirus encephalitis. Croatia: InTech; 2011. p. 235-54.

35. Mal'kova MG, lakimenko W, Tantsev AK. Changes in the ranges of pasture ixodid ticks of the genus Ixodes Latr., 1795 (Parasitiformes, Ixodinae) in Western Siberia. Parazitologiya. 2012;46:369-83. (In Russian).

36. Bakhvalova VN, Chicherina GS, Potapova OF, Panov W, Glupov W, Potapov MA, et al. Tick-borne encephalitis virus diversity in ixodid ticks and small mammals in South-Western Siberia, Russia. Vector Borne Zoonotic Dis. 2016;16:541-9

37. Morozov IM, Alekseev AN, Dubinina EV, Nikitin AY, Melnikova OV, Andaev El. Polymorphism in the phenotypic structure of a population of taiga tick and its epidemiological significance. Med Parazitol (Mosk). 2015;3:42-5. (In Russian).

38. Shchuchinova LD, Kozlova IV, Zlobin VI. Influence of altitude on tick-borne encephalitis infection risk in the natural foci of the Altai Republic, Southern Siberia. Ticks Tick Borne Dis. 2015;6:322-9.

39. Morozova OV, Cabello FC, Dobrotvorsky AK. Semi-nested PCR detection of Bartonella henselae in Ixodes persulcatus ticks from Western Siberia, Russia. Vector Borne Zoon Dis. 2004;4:306-9.

40. Shpynov SN, Fournier PE, Rudakov NV, Samoilenko IE, Reshetnikova TA, Yastrebov VK, et al. Molecular identification of a collection of spotted fever group rickettsiae obtained from patients and ticks from Russia. Am J Trop Med Hyg. 2006;74:440-3.

41. Eremeeva ME, Oliveira A, Moriarity J, Robinson JB, Tokarevich NK, Antyukova $L P$, et al. Detection and identification of bacterial agents in Ixodes persulcatus Schulze ticks from the north western region of Russia. Vector Borne Zoonotic Dis. 2007;7:426-36.

42. Fomenko NV, Livanova NN, Chernousova NY. Diversity of Borrelia burgdorferi sensu lato in natural foci of Novosibirsk region. Int J Med Microbiol. 2008;298 Suppl 1:139-48.

43. Chausov EV, Ternovoi VA, Protopopova EV, Kononova JV, Konovalova SN Pershikova NL, et al. Variability of the tick-borne encephalitis virus genome in the $5^{\prime}$ noncoding region derived from ticks Ixodes persulcatus and Ixodes pavlovskyi in Western Siberia. Vector Borne Zoonotic Dis. 2010;10:365-75.
44. Fomenko NV, Livanova NN, Borgoiakov VI, Kozlova IV, Shulaikina IV, Pukhovskaia NM, et al. Detection of Borrelia miyamotoi in ticks Ixodes persulcatus from Russia. Parazitologiya. 2010;44:201-11. (In Russian).

45. Rar VA, Livanova NN, Panov W, Doroschenko EK, Pukhovskaia NM, Vysochina NP, et al. Genetic diversity of Anaplasma and Ehrlichia in Asian part of Russia. Ticks Tick Borne Dis. 2010;1:57-65.

46. Rar VA, Epikhina TI, Livanova NN, Panov W. Genetic diversity of Babesia in Ixodes persulcatus and small mammals from North Ural and West Siberia, Russia. Parasitology. 2011;138:175-82.

47. Mikryukova TP, Moskvitina NS, Kononova W, Korobitsyn IG, Kartashov MY, Tyuten Kov OY, et al. Surveillance of tick-borne encephalitis virus in wild birds and ticks in Tomsk city and its suburbs (Western Siberia). Ticks Tick Borne Dis. 2014:5:145-51.

48. Tkachev S, Panov V, Dobler G, Tikunova N. First detection of Kemerovo virus in Ixodes pavlovskyi and Ixodes persulcatus ticks collected in Novosibirsk region, Russia. Ticks Tick Borne Dis. 2014;5:494-6.

49. Igolkina YP, Rar VA, Yakimenko W, Malkova MG, Tancev AK, Tikunov AY, et al. Genetic variability of Rickettsia spp. in Ixodes persulcatus/lxodes trianguliceps sympatric areas from Western Siberia, Russia: Identification of a new Candidatus Rickettsia species. Infect Genet Evol. 2015;34:88-93.

50. Igolkina Y, Bondarenko E, Rar V, Epikhina T, Vysochina N, Pukhovskaya N, et al. Genetic variability of Rickettsia spp. in Ixodes persulcatus ticks from continental and island areas of the Russian Far East. Ticks Tick Borne Dis. 2016;7:1284-9.

51. Mukhacheva TA, Kovalev SY. Borrelia spirochetes in Russia: Genospecies differentiation by real-time PCR. Ticks Tick Borne Dis. 2014;5:722-6.

52. Pomerantsev BI. New ticks of Ixodes family (Ixodidae). Parasit Sbornik. 1948;9: 36-46. (In Russian).

53. Kolonin GV. World distribution of ixodid ticks (genus /xodes). Nauka; 1981. p. 114

54. Filippova NA. Taxonomical aspects of studies of Ixodes Latr. ticks (Ixodidea, Ixodidae), the vectors of tick-borne encephalitis viruses. Entomol Obozrenie. 1969:48(3):675-83. (In Russian).

55. Sapegina VF, Ravkin Yu S. The finding of Ixodes pavlovskyi Pom. in North-East Altai. Parazitologiya. 1969:3:22-3. (In Russian).

56. Belyantseva Gl, Okulova NM. Seasonal changes in the activity of ixodid ticks in the natural focus of tick-borne encephalitis in the south of the Kemerovo region. Med Parasit Parasit Bolezni. 1974;43:710-5. (In Russian).

57. Kovalevskiy YV, Kuksgauzen NA, Zhmaeva ZM. Materials on Ixodes pavlovskyi Pom. distribution in Altai. Parazitologiya. 1975;9:518-21. (In Russian).

58. Livanova NN, Tikunov AY, Kurilshikov AM, Livanov SG, Fomenko NV, Taranenko DE, et al. Genetic diversity of Ixodes pavlovskyi and I. persulcatus (Acari: Ixodidae) from the sympatric zone in the south of Western Siberia and Kazakhstan. Exp Appl Acarol. 2015;67:441-56.

59. Filippova NA. Multistage mechanism of reproductive isolation of closely related species Ixodes persulcatus and I. pavlovskyi (Ixodidae) in sympatric area. Parazitologiya. 2001;35(5):361-75 (In Russian).

60. Bolotin E, Kolonin G, Kiselev A, Matjushina O. The distribution and ecology of Ixodes pavlovskyi (Ixodidae) on Sykhote-Alin. Parazitologiya. 1977;3:225-9. (In Russian)

61. Kovalev SY, Mikhaylishcheva MS, Mukhacheva TA. Natural hybridization of the ticks Ixodes persulcatus and Ixodes pavlovskyi in their sympatric populations in Western Siberia. Infect Genet Evol. 2015;32:388-95.

62. Livanova NN, Livanov SG, Panov W. Characteristics of the distribution of ticks Ixodes persulcatus and Ixodes pavlovskyi at the border between the forest and forest-steppe zones in the territory near Ob River. Parazitologiya. 2011:45:94-103. (In Russian).

63. Romanenko $V$, Leonovich S. Long-term monitoring and population dynamics of ixodid ticks in Tomsk city (Western Siberia). Exp Appl Acarol. 2015;66:103-18.

64. Romanenko VN, Kondratjeva LM. The infection of ixodid ticks collected from humans with the tick-borne encephalitis virus in Tomsk city and its suburbs. Parazitologiya. 2011;45:3-10. (In Russian).

65. Ushakova GV, Filippova NA, Panova IV. About the species of Ixodes persulcatus group (Parasitiformes, Ixodidae) IV. New data in the ecology of I. pavlovskyi Pom. from East Kazakhstan. Parazitologiya. 1969;3:436-9. (In Russian).

66. Korenberg El, Nefedova W, Romanenko VN, Gorelova NB. The tick Ixodes pavlovskyi as a host of spirochetes pathogenic for humans and its possible role in the epizootiology and epidemiology of borrelioses. Vector Borne Zoonotic Dis. 2010;10:453-8. 
67. Takano A, Toyomane K, Konnai S, Ohashi K, Nakao M, Ito T, et al. Tick surveillance for relapsing fever spirochete Borrelia miyamotoi in Hokkaido, Japan. Plos One. 2014;9:e104532.

68. Kurilshikov A, Livanova NN, Fomenko NV, Tupikin AE, Rar VA, Kabilov MR, et al. Comparative metagenomic profiling of symbiotic bacterial communities associated with Ixodes persulcatus, Ixodes pavlovskyi and Dermacentor reticulatus ticks. Plos One. 2015;10:e0131413.

69. Tkachev SE, Livanova NN. The development of system for molecular species-typing of Ixodes persulcatus and Ixodes pavlovskyi ticks. Bull SD RAMS. 2012;5:325-7. (In Russian).

70. Tkachev SE, Tikunov AY, Babkin IV, Livanova NN, Livanov SG, Panov W, et al. Occurrence and genetic variability of Kemerovo virus in Ixodes ticks from different regions of Western Siberia, Russia and Kazakhstan. Infect Genet Evol. 2017:47:56-63.

71. Postic D, Assous MV, Grimont PA, Baranton G. Diversity of Borrelia burgdorferi sensu lato evidenced by restriction fragment length polymorphism of rrf (5S)-rrl (23S) intergenic spacer amplicons. Int J Syst Bacteriol. 1994:44:743-52.

72. Margos G, Gatewood AG, Aanensen DM, Hanincová K, Terekhova D, Vollmer SA, et al. MLST of housekeeping genes captures geographic population structure and suggests a European origin of Borrelia burgdorferi. Proc Natl Acad Sci USA. 2008;105:8730-5.

73. Sumner JW, Nicholson WL, Massung RF. PCR amplification and comparison of nucleotide sequences from the groESL heat shock operon of Ehrlichia species. J Clin Microbiol. 1997;35:2087-92.

74. Liz JS, Anderes L, Sumner JW, Massung RF, Gern L, Rutti B, et al. PCR detection of granulocytic ehrlichiae in Ixodes ricinus ticks and wild small mammals in western Switzerland. J Clin Microbiol. 2000;38:1002-7.

75. Kumar S, Stecher G, Tamura K. MEGA7: Molecular evolutionary genetics analysis version 7.0 for bigger datasets. Mol Biol Evol. 2016;33:1870-4.

76. Khasnatinov MA, Danchinova GA, Kulakova NV, Tungalag K, Arbatskaia EV, Mironova LV, et al. Genetic characteristics of the causative agent of tickborne encephalitis in Mongolia. Vopr Virusol. 2010;55:27-32. (In Russian).

77. Kurilshikov AM, Fomenko NV, Stronin OV, Tikunov AY, Kabilov MR, Tupikin $A E$, et al. Complete genome sequencing of Borrelia valaisiana and Borrelia afzelii isolated from Ixodes persulcatus ticks in Western Siberia. Genome Announc. 2014;2:e01315-14.

78. Fomenko NV, Sabitova IB, Khasnatinov MA, Gol'tsova NA, Danchinova GA, Bataa Z, et al. Heterogeneity of the gene P83/100 of Borrelia burgdorferi sensu lato complex. Mol Gen Mikrobiol Virusol. 2007:4:31-7. (In Russian).

79. Geller J, Nazarova L, Katargina O, Järvekülg L, Fomenko N, Golovljova I. Detection and genetic characterization of relapsing fever spirochete Borrelia miyamotoi in Estonian ticks. Plos One. 2012;7:e51914.

80. Rar VA, Epikhina TI, Livanova NN, Panov W, Doroschenko EK, Pukhovskaia NM, et al. Genetic variability of Anaplasma phagocytophilum in Ixodes persulcatus ticks and small mammals in the Asian part of Russia. Vector-Borne Zoonotic Dis. 2011;11:1013-21.

81. Ushakova GV, Filippova NA. On the species of Ixodes persulcatus group (Parasitiformes, Ixodidae) II. On the ecology of I. pavlovskyi Pom. from East Kazakhstan. Parazitologiya. 1968;2:334-8. (In Russian).

82. Lesnyak O, Laikovskaya E, Kufko I, Bruinink H, Baranova N, Rijpkema S. Clinical features of Lyme borreliosis in the middle Urals and distribution of Borrelia burgdorferi sensu lato species in local Ixodes persulcatus ticks. Zentralbl Bakteriol. 1998;288:111-9.

83. Spitalská E, Boldis V, Kostanová Z, Kocianová E, Stefanidesová K. Incidence of various tick-borne microorganisms in rodents and ticks of central Slovakia. Acta Virol. 2008:52:175-9.

84. Schmidt JR, Shope RE. Kemerovo virus from a migrating common redstart of Eurasia. Acta Virol. 1971;15:112.

85. Bown KJ, Lambin X, Ogden NH, Begon M, Telford G, Woldehiwet Z, et al Delineating Anaplasma phagocytophilum ecotypes in coexisting, discrete enzootic cycles. Emerg Infect Dis. 2009;15:1948-54.

86. Blaňarová L, Stanko M, Carpi G, Miklisová D, Víchová B, Mošanský L, et al Distinct Anaplasma phagocytophilum genotypes associated with Ixodes trianguliceps ticks and rodents in Central Europe. Ticks Tick Borne Dis. 2014:5:928-38.

87. Rar VA, Epikhina TI, Yakimenko W, Malkova MG, Tancev AK, Bondarenko EI, et al. Genetic variability of Anaplasma phagocytophilum in ticks and voles from Ixodes persulcatus/lxodes trianguliceps sympatric areas from Western Siberia, Russia. Ticks Tick Borne Dis. 2014:5:854-63.
88. Lundkvist K, Vene S, Golovljova I, Mavtchoutko V, Forsgren M, Kalnina V, et al. Characterization of tick-borne encephalitis virus from Latvia: evidence for co-circulation of three distinct subtypes. J Med Virol. 2001;65:730-5.

89. Katargina O, Russakova S, Geller J, Kondrusik M, Zajkowska J, Zygutiene M, et al. Detection and characterization of tick-borne encephalitis virus in Baltic countries and eastern Poland. Plos One. 2013;8:e61374.

90. Khasnatinov MA, Tuplin A, Gritsun DJ, Slovak M, Kazimirova M, Lickova M, et al. Tick-borne encephalitis virus structural proteins are the primary viral determinants of non-viraemic transmission between ticks whereas nonstructural proteins affect cytotoxicity. Plos One. 2016;11:e0158105.

\section{Submit your next manuscript to BioMed Central and we will help you at every step:}

- We accept pre-submission inquiries

- Our selector tool helps you to find the most relevant journal

- We provide round the clock customer support

- Convenient online submission

- Thorough peer review

- Inclusion in PubMed and all major indexing services

- Maximum visibility for your research

Submit your manuscript at www.biomedcentral.com/submit
Biomed Central 